ORNL/CSD-118

\title{
Mathematics and Statistics Research Progress Report \\ Period Ending June 30, 1983
}

\section{DO NOT MICROFILM THIS PAGE}

OPERATED BY

UNION CARBIDE CORPORATION FOR THE UNITED STATES DEPARTMENT OF ENERGY 


\section{DISCLAIMER}

This report was prepared as an account of work sponsored by an agency of the United States Government. Neither the United States Government nor any agency Thereof, nor any of their employees, makes any warranty, express or implied, or assumes any legal liability or responsibility for the accuracy, completeness, or usefulness of any information, apparatus, product, or process disclosed, or represents that its use would not infringe privately owned rights. Reference herein to any specific commercial product, process, or service by trade name, trademark, manufacturer, or otherwise does not necessarily constitute or imply its endorsement, recommendation, or favoring by the United States Government or any agency thereof. The views and opinions of authors expressed herein do not necessarily state or reflect those of the United States Government or any agency thereof. 


\section{DISCLAIMER}

Portions of this document may be illegible in electronic image products. Images are produced from the best available original document. 


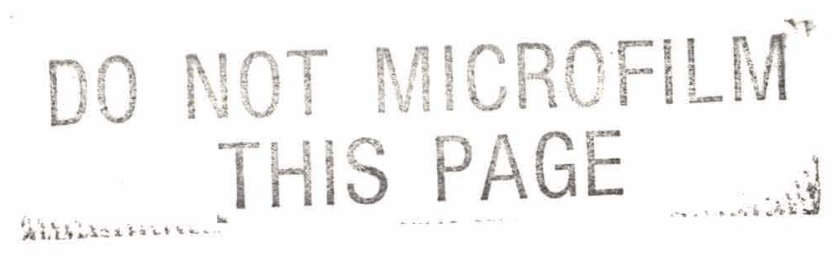
Pririted in the Unitod States of America Available from National Technical Information Service
U.S. Department of Commerce
5285 Port Royal Road, Springfield, Virginia 22161
NTIS price codes-Printed Copy: A06 Microfiche A01

This report was prepared as an account of work sponsored by an agency of the United States Government. Neither the United States Government nor any agency thereof, nor any of their employees, makes any warranty, express or implied, or assumes any legal liability or responsibility for the accuracy, completeness, or usefulness of any information, apparatus, product, or process disclosed, or represents that its use would not infringe privately owned rights. Reference herein to any specific commercial product, process, or service by trade name, trademark, manufacturer, or otherwise, does not necessarily constitute or imply its endorsement, recommendation, or favoring by the United States Government or any agency thereof. The views and opinions of authors expressed herein do not necessarily state or reflect those of the United States Government or any agency thereof. 
ORINL/CSO-118

Distribution Category UC-32

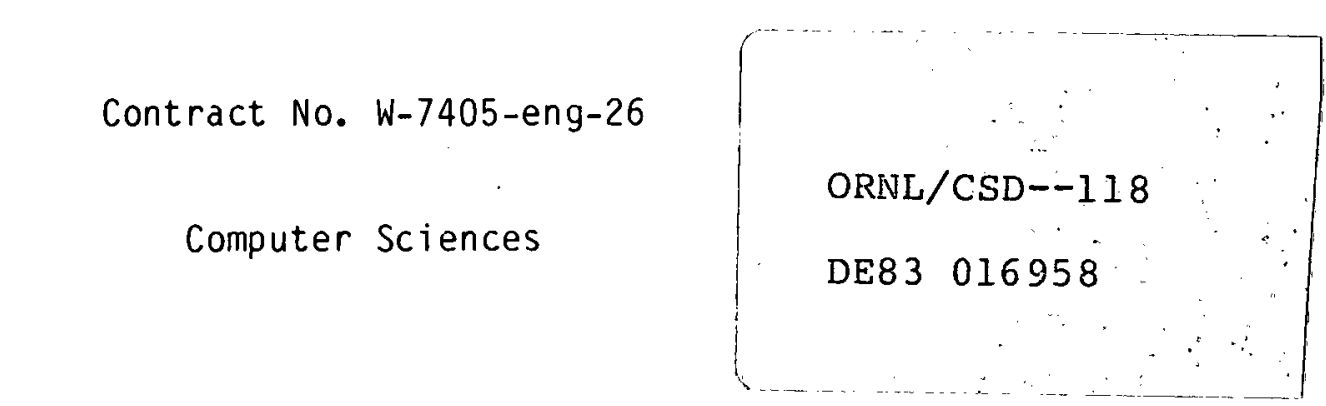

MATHEMATICS AND STATISTIICS RESEARCH

PROGRESS REPORT

Period Ending June 30, 1983

R. C. Ward, Head

Compiled and edited by

J. J. Beauchamp

M. V. Denson

M. T. Heath

W. E. Lever

D. G. Wilson

Date Published: August 1983

Work performed at Oak Ridge National Laboratory

P.0. Box $X$, Oak Ridge, TN 37830

\section{UNION CARBIDE CORPORATION - NUCLEAR DIVISION \\ operating the}

-0ak Ridge Gaseous Diffusion Plant -0ak Ridge National Laboratory

- Oak Ridge Y-12 Plant -Paducah Gaseous Diffusion Plant

for the

Department of Energy 
Reports previously issued in this series are as follows:

ORNL-2283
ORNL-2652
ORNL-2915
ORNL-3082
ORNL-3264
ORNL-3423
ORNL-3567
ORNL-3766
ORNL-3919
ORNL-4083
ORNL-4236
ORNL-4385
ORNL-4514
ORNL-4661
ORNL-4761
ORNL-4851
ORNL-4989
UCCND/CSD-18
ORNL/CSD-13
ORNL/CSD-27
ORNL/CSD-34
ORNL/CSD-40
ORNL/CSD-61
ORNL/CSD-82
ORNL/CSD-105

Period ending February 28, 1957

Period ending August 31, 1958

Period ending December 31, 1959

Period ending December 31,1960

Period ending January 31, 1962

Period ending December 31, 1962

Period ending December 31, 1963

Period ending December 31, 1964

Period ending December 31, 1965

Period ending necember 31, 1966

Period ending December 31, 1967

Perind ending December 31,1968

Period ending December 31, 1969

Period ending December 31,1970

Period ending December 31, 1971

Period ending December 31, 1972

Period ending June 30,1974

Period ending June 30, 1975

Period ending June 30,1976

Period ending Ilune 30, 1977

Period ending June 30, 1978

Period ending June 30,1979

Period ending June 30,1980

Period ending June 30,1981

Period ending June 30, 198 .

\section{DISCLAIMER}

This report was prepared as an account of work sponsored by an agency of 1.1r. Inited Statos Ouvermment. Nelther the United States Government nor any agency thereof, nor any of their employees, makes any warranty, express or implied. or assumes any legal liability or respousibility tor the accuracy, complcteness, or usefulness of any information, apparatus, product, or process disclosed, or represents that its use would not infringe privately owned rights. Reference herein to any specific commercial product, process, or service by trade name, trademark, manufacturer; or otherwise does not necessarily constitute or imply its endorsement, rexounmondation, or lavoring by the United States Government or any agency thereof. The views and opinions of authors expressed herein do not necessarily state or reflect those of the United States Government or any agency thereof. 


\section{CONTENTS}

PREFACE . . . . . . . . . . . . . . . . . . . . SUMMARY ......................... XV

\section{PART A. MATHEMATICAL AND STATISTICAL RESEARCH}

1. ANALYSIS OF LARGE DATA SETS . . . . . . . . . . 1 Comparison of Discrimination Models . . . . . . . . . 1 Data-Based Transformations .............. . 2 Bayesian Regression in the Presence of Multicollinearity . . 4 Optimization of Retention Probability With PSS Sampling From Updated Frames ................... 5 References .................. 6

2. APPIIED ANALYSIS . . . . . . . . . . . . . 7 Moving Boundary Problems ................... . 7 Stochastic Analysis .................. 8 References .................... 9

3. BIOMETRICS RESEARCH ................. 11 Nonparametric Bioassay. . . . . . . . . . . . . 11 A Computer Program for the Analysis of Disease. Prevalence Data .................. 11 Sample Mean of Correlated Observations . . . . . . . 12 Relative Risk Estimation Using Poisson Regression Models . . 13 
Maximum Likelihood Estimation for Cytogenetic

Dose Response Curves ................. 13

References.................... . 14

4. COMPUTATIONAL STATISTICS . . . . . . . . . . 15

Compromise Designs for Estimation and Detection of

Lack of Fit . . . . . . . . . . . . . 15

Compromise Designs for Factorial Experiments . . . . . 16

Minimum Size of Search Designs .. . . . . . . . . . 17

A Graphical Interpretation of Stein's Phenomenon . . • . . 17

Maximum Likelihood [stimator of Gamma Distributiür . . . . 18

Computation of the Polygamma Functions . . . . . , . . 18

Computerized Faa di Bruno's Formula . . . . . . . . . 18

An Algorithm for Linear Dependency Analysis . . . . . . . 19

References. . . . . . . . . . . . . . 20

5. MATERIALS SCIENCE APPLICATIONS . . . . . . . . . 22

Inclined Pileup of Screw Dislocations at Crack Tip . . . . 22

References. . . . . . . . . . . . . . 23

6. NUMERICAL LINEAR Algebra. . . . . . . . . . . ? ?4

Sparse Least Squares Problems . . . . . . . . . . . 24

The Force Method for Structural Analysis . . . . . . . 24

Sparse Matrix Software Catalog . . . . . . . . . . 25

Computational Methods for Singular Irreducible M-Matrices . • 25

References.................. 26

7. RISK ANALYSIS . . . . ............ 27

Man and Machine: Probabilistic Learning Models . . . • • • 27

Propagation of Uncertainties . . . . . . . . . 28

References................ . . . 29 
PART B. STATISTICAL AND MATHEMATICAL COLLABORATION

8. BIOLOGICAL SCIENCES ................... 31

Diesel Fuel Aerosols ................. 31

Binding of Monocional Antibody to Tumor Cells . . . . . . 32

Relative Biological Efficiency (RBE) of Fission Neutrons

at Low Doses for Life Shortening in Mice . . . . . . . . 32

Cell Transplantation Bioassay . . . . . . . . . . 33

Levels of Significance of Tests on Small Proportions . . . . 34

Toxicity of Metal Ions . . . . . . . . . . . . 34

Circadian Rhythm in Mitotic Cell Frequencies ....... 35

References................. 35

9. ENERGY . . . . . . . . . . . . . . . . . 37

Software for Computer-Aided Control System Design . . . . . 37

Development of the EIA Sampling Frame of Distillate

and Residual Fuel 0 il Dealers (EIA-764) . . . . . . . . 37

Sampling Plan for Form EIA-64A System Assessment . . . . . 38

References.................. 39

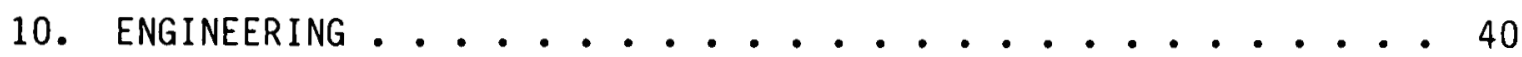

Plating and Electrochemical Machining .......... 40

Latent-Heat Thermal Energy Storage. . . . . . . . . . 40

Rotor Forced Response, Natural Frequencies, Balancing . . . . 41

Development of "Intelligent" Robotic Devices . . . . . . 4 42

Confidence Limits for the Expectation of a Poisson Variate . 43

References................. 43

11. EnVIRONMENTAL SCIEnCES. . . . . . . . . . . 45

Effects of Coal-Derived $0 i 1$ on a Freshwater Ecosystem . . . . 45

Influence of Stemflow on the Distribution of Soil Sulfate . . 46

Effect of Petroleum and Synthetic 0ils on Reproduction

of the Milkweed Bug ............... . . 47

Analysis of Phosphorus Deficiency Patterns . . . . . . 48

Effects of a Coal Liquid on Emergence of Pond Insects . . . . 49 
Predator-Prey Model . . . . . . . . . . . . 50

Combining Uncertainties in Environmental Risk Assessment . . 50

References.................. 51

12. HEALTH AND SAFETY . . . . . . . . . . . . . . 52

Cancer Incidence Rates in Radiation-Exposed Populations . . . 52

Cardiovascular Disease and Mineral Elements in

Drinking Water. . . . . . . . . . . . . . 52

Acceptance Sampling Plan for Raschig Rings . . . . . . 53

Callbration of TLD Badges ............. 53

Graphical Display of Air Monitoring Data . . . . . . . 53

Tolerance Limits for Simulated K-Effectives . . . . . . . 54

References................. 54

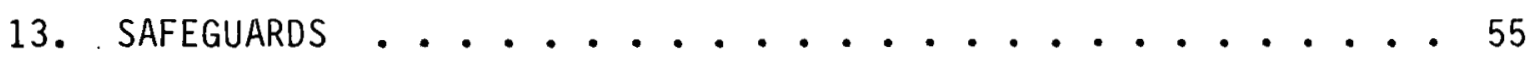

Proposed NRC Regulations and Loss Detection

Capabilities in Reprocessing Plants . . . . . . . . . 55

Calculating Control Limits for Inventory Differences . . . 56

Shading by a Rectangle . . . . . . . . . . . 56

References. . . . . . . . . . . . . . 56

\section{PART C. EDUCATIONAL ACTIVITIES}

Workshops and Conferences . . . . . . . . . . . 57

In-House Education Programs . . . . . . . . . . . . . 58

Seminar Series . . . . . . . . . . . . . . . 60

Traveling Lecturers .................. . . 60

Supervision of Students. . . . . . . . . . . . 60

University Teaching Activities . . . . . . . . . . . . 61

Short-Term Visiting Researchers. . . . . . . . . . . 62

Long-Term Visiting Researchers . . . . . . . . . . . 62

List of Consultants. . . . . . . . . . . . . . . 64

MSR Seminars . . . . . . . . . . . . . . . . . . 64

ORAU Traveling Lecture Presentations . . . . . . . . . . . 66

COPSS Traveling Lecture Presentations . . . . . . . . . 66 
PART D. PRESENTATIONS OF RESEARCH RESULTS

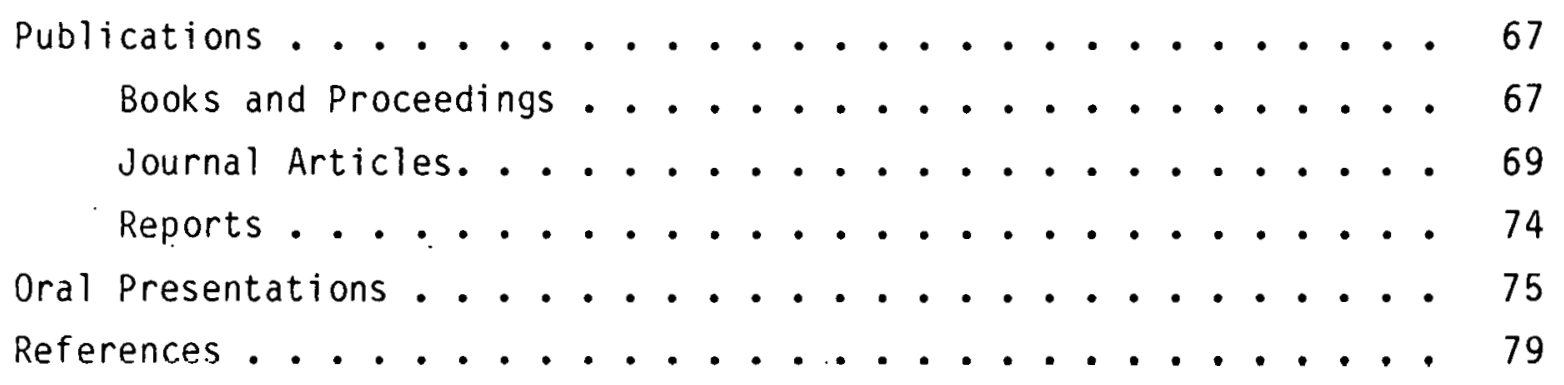

\section{PART E. PROFESSIONAL ACTIVITIES}

List of Professional Activities. . . . . . . . . . . . . 81 Table of Articles Reviewed or Refereed for Periodicals . . . . . 87 


\section{PREFACE}

\section{OPERATIONS}

During the 12 months ending June 30, 1983, Mathematics and Statistics Research (MSR) logged 35,497 hours of effort in research and service to the components of Union Carbide Corporation Nuclear Division (UCC-ND) and other local U. S. Department of Energy (DOE) contractors. Of the effort expended, $41 \%$ was on projects managed by MSR, $35 \%$ was for consulting and collaboration with the Oak Ridge National Laboratory (ORNL) divisions, $21 \%$ was for the UCC-ND production and technical support staff, and $3 \%$ was for all other activities. This distribution of effort is shown in the figure below.

ORNL-DWG 83-2907 FED

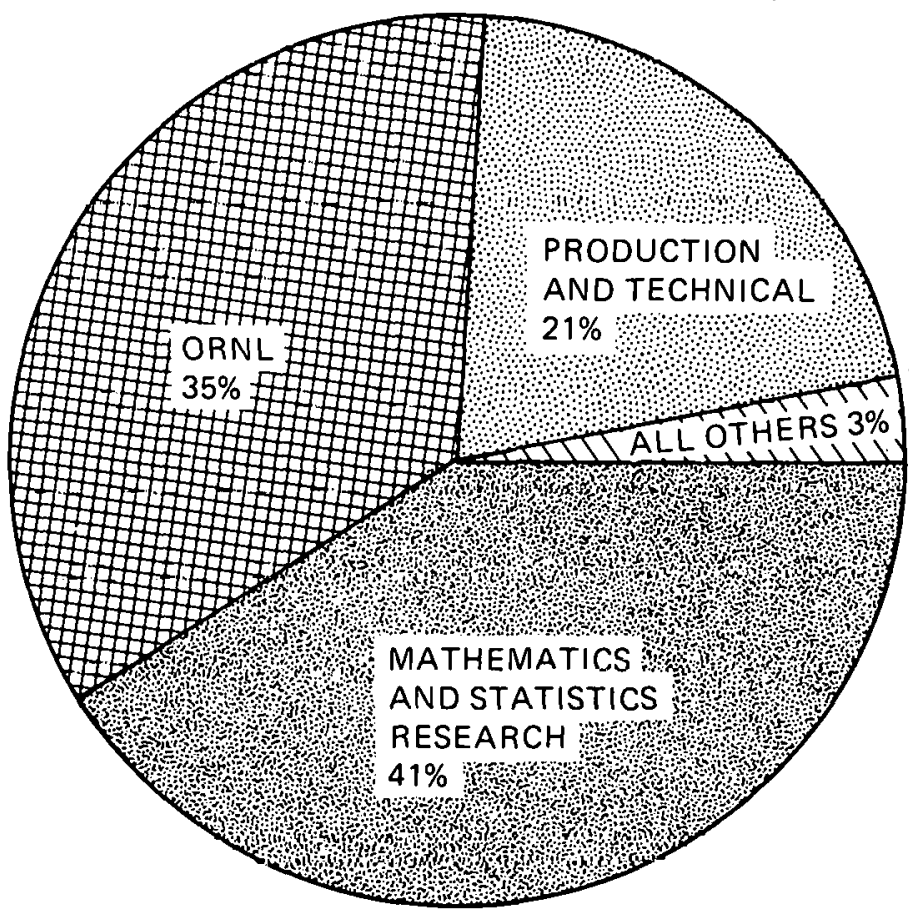

Distribution of Mathematics and Statistics Research Effort 
The research projects managed by MSR during this period included five projects funded by the DOE Office of Basic Energy Sciences, two funded by the DOE Office of Health and Environmental Research, one by the Nuclear Regulatory Commission, and one by the National Geodetic Survey. The figure below shows the distribution of hours charged to these projects. The progress made in these projects is described in the appropriate chapters of this report.

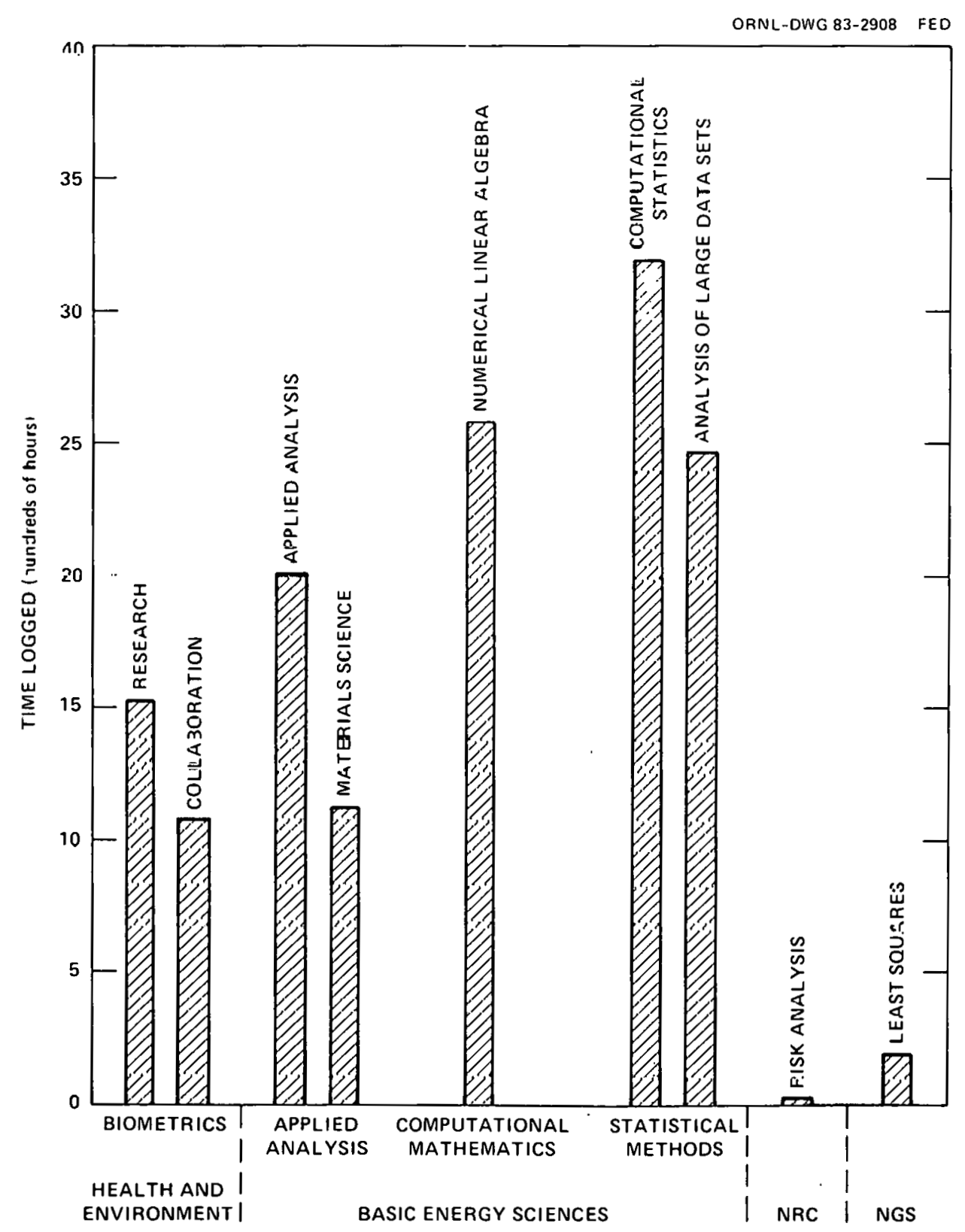


Research in the Applied Analysis Category for the DOE Office of Basic Energy Sciences has been reorganized during this report period to reflect current MSR research directions. Research in the Materials Science Project has been discontinued, and a new project entitled Applied Analysis has been formed. This new project includes our research on moving boundary problems and a new initiative on problems in stochastic analysis. Thus, the former Moving Boundary Problems Project has also been dissolved, being subsumed by the new project.

of the total time logged by the department staff, $56 \%$ was devoted to assisting scientists and engineers in other units of UCC-ND. The distribution of this effort is shown in the bar chart below.

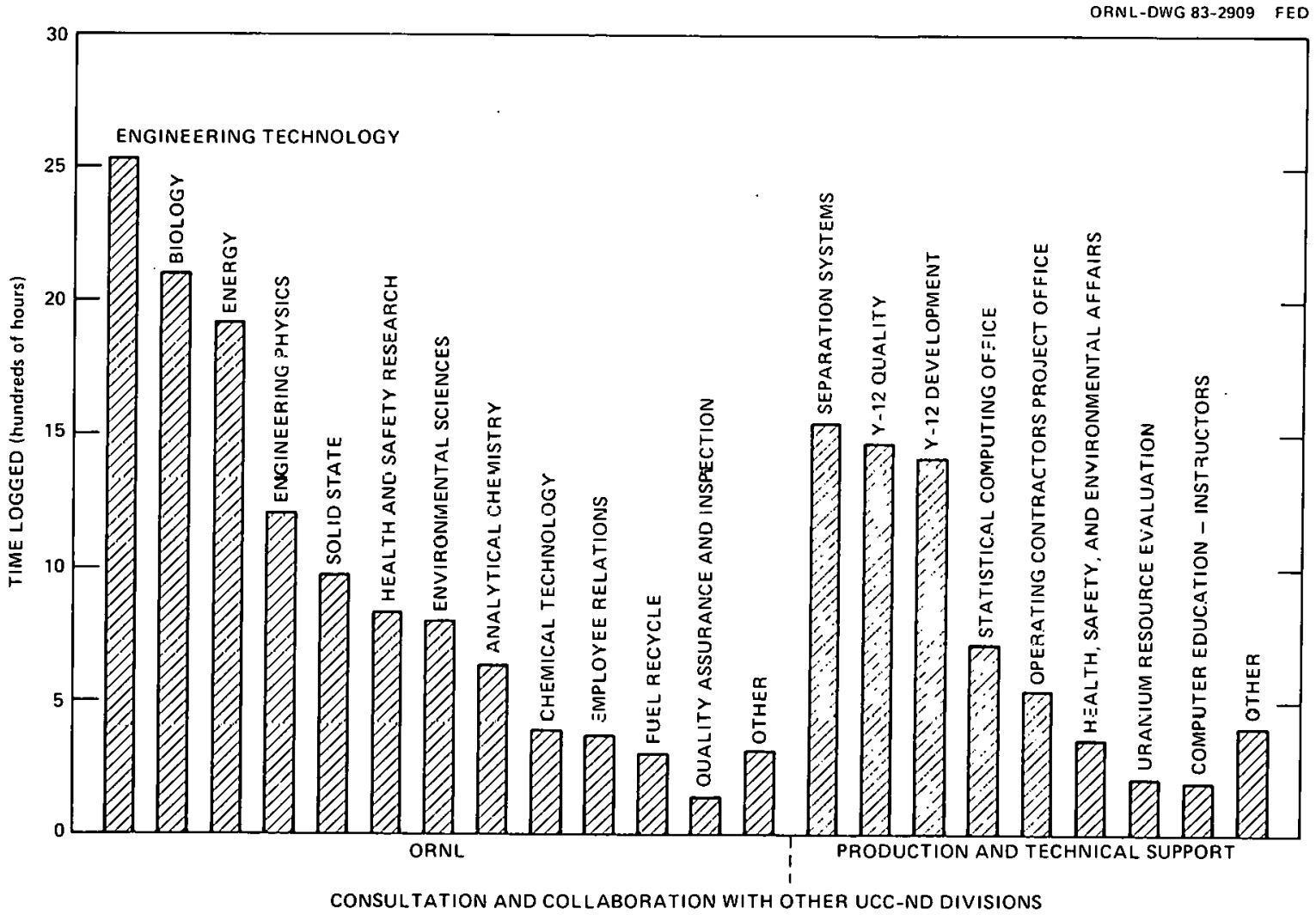




\section{PERSONNEL}

Several personnel changes took place during the past 12 months. D. A. Gardiner transferred to the $Y-12$ Plant accepting a position as Senior Staff Consultant. P. K. Stuber returned to Tennessee Technological University to continue her studies toward an undergraduate degree. C. K. Bayne, S.-J. Chang, M. H. Hsie, and C. B. Yount transferred to Technical Applications of Computer Sciences, Engineering Technology Division, Information Systems of Computer Sciences, and Central Staff of Computer Sciences, respectively. V. E. Kane accepted an employment offer from the Ford Motor Company.

New employees are G. A. Geist and M. L. Stephens in the Mathematics Section, D. L. Poole in the Secretarial Support Section, and D. C. Schlotzhauer in Statistics Section B.

Several changes also occurred in the management of MSR. R. C. Ward accepted the position of Head of Mathematics and Statistics Research; D. G. Gosslee agreed to reassume some management duties and accepted the position of Acting Head of Statistics Section A; and A. D. Solomon accepted the position of Head of the Mathematics Section. The current organization chart is shown on the following paye. 
ORNL-DWG 82-12475R3

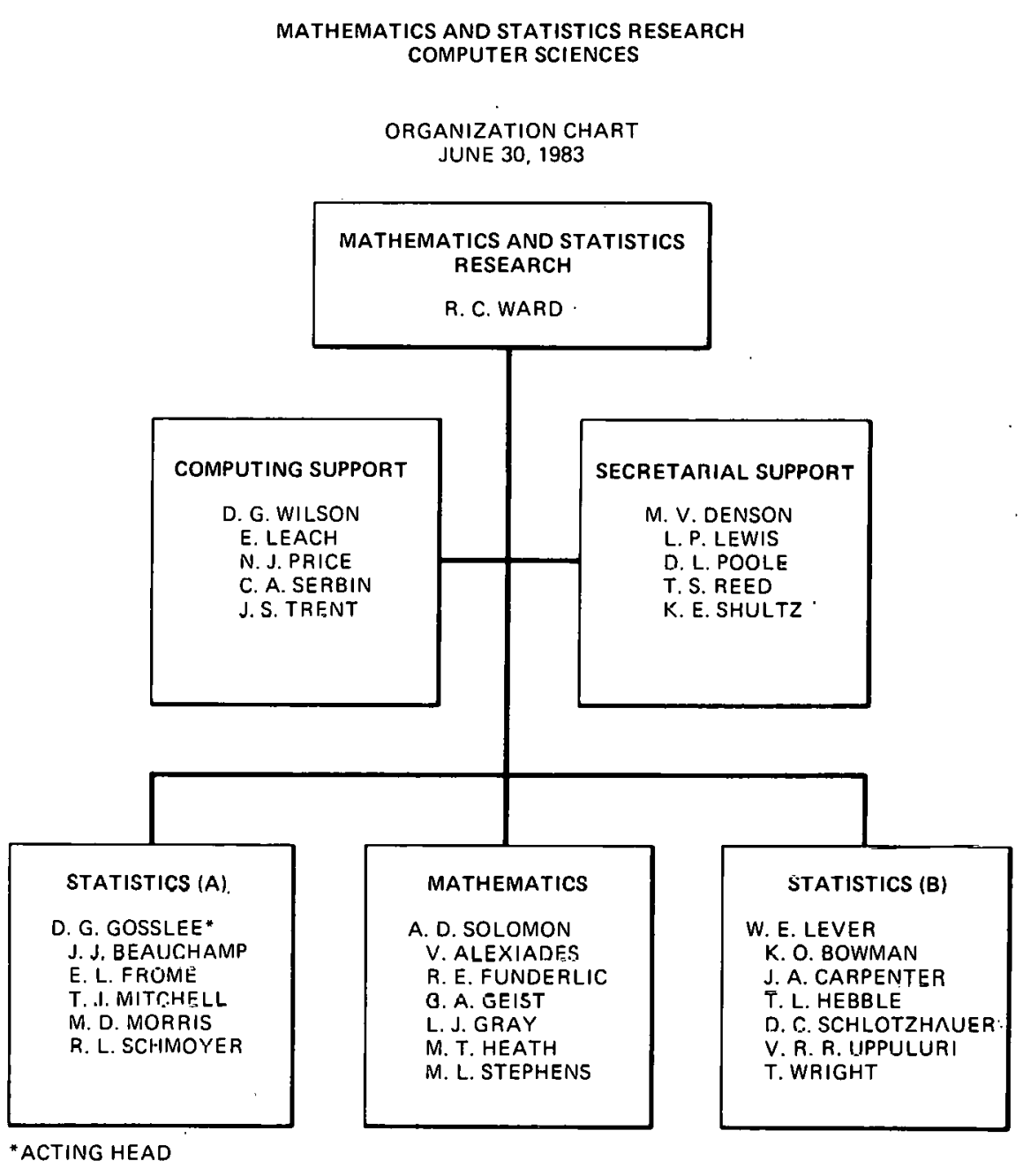




\section{SUMMARY}

This report is the twenty-sixth in the series of progress reports of Mathematics and Statistics Research of the Computer Sciences organization, Union Carbide Corporation Nuclear Division.

Part A records research progress in analysis of large data sets, applied analysis, biometrics research, computational statistics, materials science applications, numerical linear algebra, and risk analysis.

Collaboration and consulting with others throughout the Oak Ridge Department of Energy complex are recorded in Part B. Included are sections on biological sciences, energy, engineering, environmental sciences, health and safety, and safeguards.

Part $C$ summarizes the various educational activities in which the staff was engaged. Part $D$ lists the presentations of research results, and Part $E$ records the staff's other professional activities during the report period. 
PART A. MATHEMATICAL AND STATISTICAL RESEARCH

\title{
1. ANALYSIS OF LARGE DATA SETS
}

\author{
C. K. Bayne ${ }^{1}$ \\ J. J. Beauchamp \\ N. R. Draper ${ }^{2}$ \\ L. J. Gray, \\ V. E. Kane 3 \\ G. P. McCabe ${ }^{4}$
}

T. J. Mitchell

C. A. Serbin

H. Tsao

T. Wright

\section{COMPARISON OF DISCRIMINATION MODELS}

Work has continued on comparing the performance of Fisher's linear and quadratic discriminant functions with the logistic linear and quadratic discriminant functions for classifying observations from three types of bivariate distributions. ${ }^{6}$ The simulation study results provided the following generalizations: (1) lhe opt1mal maximum likelihood procedure is preferable for the data types considered, but requires distributional modeling; (2) the standard linear discriminant function (LDF) is least sensitive to small sample sizes; (3) the quadratic discriminant function's (QDF) distributional robustness depends upon the type of nonnormality present and its performance was found to be sensitive to sample size; and (4) the logistic procedures (LLF and QLF) perform poorly for small misclassification probabilities $\left(p_{T} \leq 0.15\right)$ and small sample sizes $(n \leq 25)$ even though, theoreticially, they are distributionally robust for the exponential family when the discrimination model is correct. A theoretical explanation ror the 
poor performance of the LLF for small values of $\mathrm{p}_{T}$ in the bivariatenormal-equal-covariance case was derived from an examination of some logistic regression diagnostics given by Pregibon. 7 The theoretical explanation demonstrated that only a few "outlier" observations that can occur between two separated populations can have an appreciable influence on the estimated parameters of the LLF. Figure 1 shows a comparison of the performance of the LDF to other discriminant functions using the mean square error (MSE) and bias ratios. This figure demonstrates the importance of selecting the appropriate function for the discriminatlun pioblem.

The algorithm ${ }^{8}$ developed to calculate the misciassiftcalion probabilities for the second-order discriminant functions used to classify observations from bivariate normal populations has been updated to make use of currently available subroutines. The computer program has been extensively tested to ensure that the prograin adheres to a portable subset of ANSI FORTRAN 66.

\section{DATA-BASED TRANSFORMATIONS}

In the traditional approach to classification using discriminant analysis, a lraisformation is selected without regard for the transformation's effect on misclassification probabilities. Research has started on the application of the power transformation to bivariate observations from two populations and the examination of estimated misclassification probabilities when consideration is restrlcled lo a linear discriminant function. A computer algorithm has been written to obtain the marginal as well as joint maximum likelinood estimates of the power transformation parameters for a given data set. Modifications to the algorithm have also been made to allow for "jackknite"= like estimates of the transformation parameters and misclassification probabilities to be obtained as well as resubstitution estimates of the misclassification probabilities. In addition, estimates of the misclassification probabilities for the untransformed data are obtained for comparative purposes. The difference between the estimated 

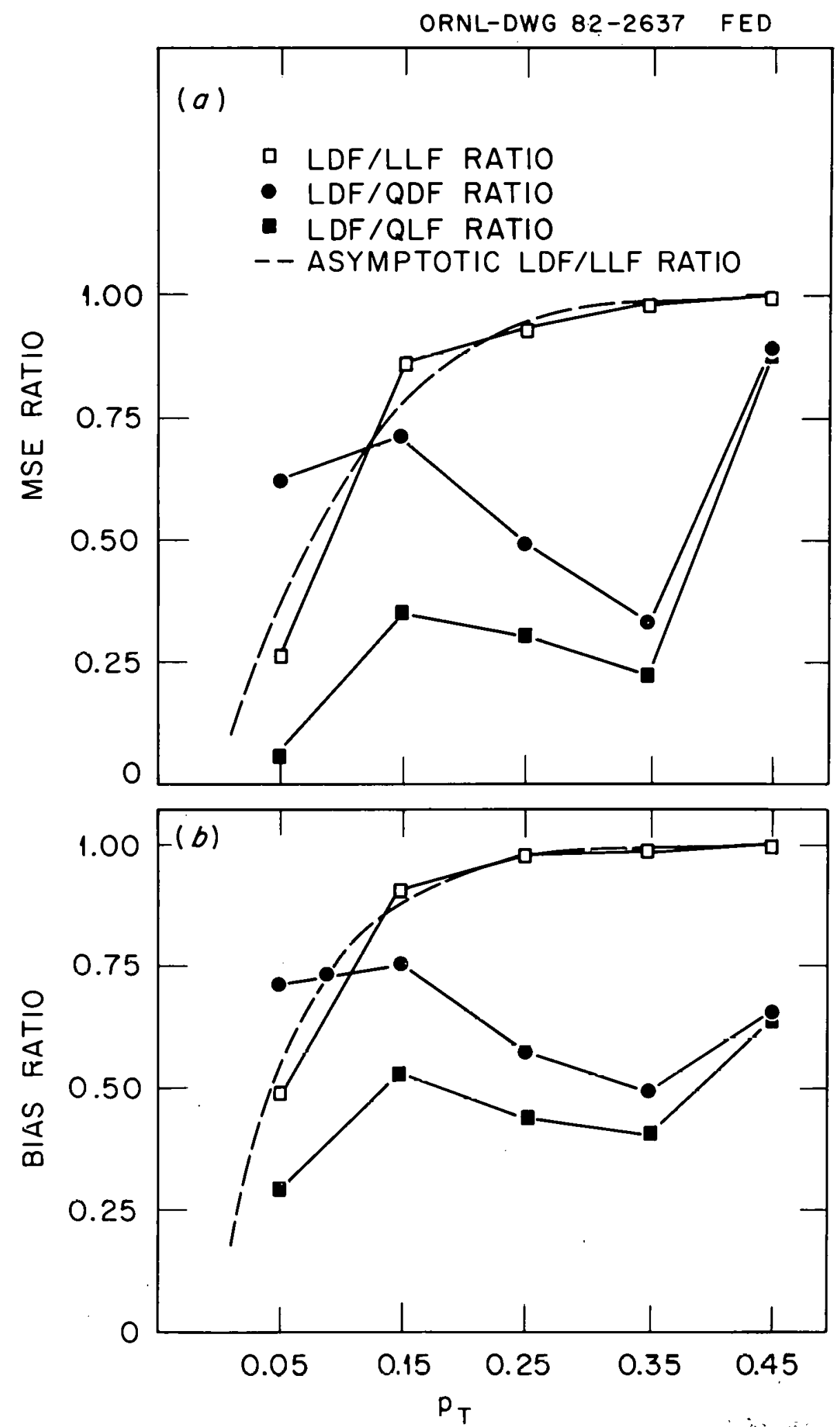

Fig. 1. MSE and bias ratio vs $p_{T}$ for bivariate normal data with equal covariance matrices $(n=100)$. 
misclassification probabilities from the transformed and untransformed data can form the basis for an evaluation of the effect of the transformation. A simulation study has been done to examine the effect of the transformation when the correct transformation to achieve normality is known. Preliminary results froin the simulation study indicate for values of the transformation parameter in the $[0,1]$-interval that the major effect of the transformation is found for values near 0 where the difference between the transformed and untransformed misclassification probabilities can be more than $50 \%$ when consideration is restricted to d linear discriminant function.

\section{BAYESIAN RCGRESSION IN THE PRF.SENCE OF MULICOLLINEARITY}

Large data sets based on observation of physical or econonic processes rather than on designed experiments frequently exhibit "multicollinearity"; i.e., the observed values of some of the variables can be very nearly approximated by linear combinations of the values of other variables. If several of the "explanatory" variables happen to be multicollinear, this causes great difficulty in regression analyses

of such data sets. In essence, there is not enough information in the data to determine with adequate precision the individual effects of these variables un llie "respunse" variahte.

The Bayesian way of dealing with this problem is to bring in additional "information" by means of a prior distribution on the vector of regression coefficients, $\beta$. Usually a llulliciormal distribution ic chosen because theoretical results in the form of formulas for the relevant posterior distributions are readily available. The main practical problem in this case is the choice of the prior mean and covariance matrix. We have shown, that this choice can be made easily if one is willing to specify a priori that the true response values of interest are normally distributed, independently and identically. The responses "of interest" may include ruture values and hypothetical cases as well as data already observed. Imposing the model assumptions on this prior distribution then generates the appropriate prior on $\underset{\sim}{\beta}$; 
the mean and covariance matrix (up to a multiplicative constant) of this distribution are completely specified. The subsequent analysis yields a special kind of "ridge estimator", which in certain special cases can be shown equivalent to the "shrinkage estimator" and the Hoerl-Keninard ridge estimator. Both of these estimators are popular alternatives to the least-squares estimator when multicollinearity is present. The advantage of the present approach is that it can be used much more generally in settings where neither of these estimators is appropriate.

\section{OPTIMIZATION OF RETENTION PROBABILITY WITH PPS SAMPLING FROM UPDATED FRAMES}

A classical problem in sampling from a finite stratified population is the estimation of a population total, $Y$, where it is important that the random choice of a unit from the stratum be made with probability proportional to the measure of size (PPS) of that unit. When sampling frames, such as that which supports Form EIA-782B (formerly called Form EIA-9A), are updated, the measures of size associated with the population units frequently will change due to net growth, births, deaths, and mergers. Since these measures of size can be used in estimation, efficiency requirements dictate that significant relative changes in size should be followed by an updated sample. Because of the high cost of obtaining accurate auxiliary information on new respondents and of familiarizing them with reporting procedures, it is often desirable to retain as many respondents as possible from the original sample (based on the outdated measures of size) for the new sample (based on the updated measures of size). Keyfitz ${ }^{9}$ and Cohen ${ }^{10}$ have considered this problem when one unit is to be selected from each stratum.

We have demonstrated that a linear programming approach solves not only the problem of maximizing the probability of retention, but also that the linear programming approach can be used to solve other related problems, including the problem of minimizing the probability of retention. We have shown that Keyfitz's solution is only one of the 
possibly infinite solutions offered by the linear programming approach. We also have shown how the technique of linear programming can be used with PPS sampling when one selects two units from each stratum without replacement.

\section{REFERENCES}

${ }^{1}$ Technical Applications.

${ }^{2}$ University of Wisconsin.

${ }^{3}$ Ford Motor Company.

${ }^{4}$ Purdue University.

EEnergy Division.

"Comparison of Discrimination Models," Mathematics and Statistics Research Department Progress Report, Period Ending June 30, 1982, ORNL/CSD-105, pp. 2-3 (August 1982).

7D. Pregibon, "Logistic Regression Diagnostics," The Annals of Statistics, 9, 705-724 (1981).

"Calculating Misclassification.Probabilities," Mathematics and Statistics Research Department Progress Report, Period Ending June 30,1981, ORNL/C SD-82, p. 12 (Seplemiber 1981).

${ }^{9}$. Keyfitz, "Sampling with Probabilities Proportionate to Size Adjustment for Changes in the Probabilities," Journal of the American Statistical Association, 46, 105-109 (1951).

${ }^{10}$ S. E. Cohen, "A Device for Sampling from Finite Populations on Successive Occasions," The American Statistician, 23(4), 26-27 (1969). 


\section{APPLIED ANALYSIS}
V. Alexiades
C. A. Serbin
L. J. Gray
T. Kaplan
A. D. Solomon
R. Mills $\mathrm{s}^{2}$
D. G. Wilson

\section{MOVING BOUNDARY PROBLEMS}

Our major attention has continued to be focused on binary alloy solidification. Significant questions of both mathematical and practical importance revolve around the existence and behavior of "mushy" regions in the neighborhood of the solid/liquid boundary. We have attempted to confront these problems by introducing a number of alternative models of material activity in such a region. We believe that we have succeeded in developing a theoretically consistent mathematical model of binary alloy solidification ${ }^{3}$ which includes the possibility of mushy regions but does not require their existence. Additional effort was expended in a systematic investigation of existing numerical methods for solving moving boundary problems. A great variety of such methods exist, ranging from schemes for explicitly tracking a moving front to weak solution approaches. A survey paper ${ }^{4}$ is in preparation which will present a comparison and evaluation of numerous different methods. Other results of our work during the past year include: the extension of the enthalpy method to the case of a region consisting of a number of regions with different thermophysical properties; continued expansion of our bibliographic files on moving boundary problems; and some success in implementing adaptive learning techniques for boundary value problems involving the heat equation.

We have developed a new formulation of the mathematical model for binary alloy solidification. This model is based on a noncquilibrium thermodynamic analysis of the physical process. Its salient feature is the appearance of a new variable the "liquid fraction" of material. This variable takes values in the closed interval $[0,1]$ with 0 corresponding to the solid phase, 1 corresponding to the liquid phase, and 
intermediate values corresponding to a mushy region. The liquid fraction is defined by the classical Lever rule involving the temperature, concentration and phase diagram relations. The liquid fraction appears explicitly in the conservation relation for energy. The mathematical problem consists of a pair of coupled nonlinear parabolic partial differential equations, which are to hold in a distributional sense in the entire alloy region, together with appropriate initial and boundary conditions. Analysis of this model is proceeding on two fronts. We are investigating the usual theoretical questions of existence, uniqueness, and continuous dependence of solutions for the mathematical problem; and we are implementing the mndel in a r.nmputer algorithm to gain some numerical experience with it.

We have initiated a study of numerical methods for moving boundary problems. The object of this study is to identify which methods are suitable for which kinds of problems. A few of the approaches being evaluated are: the variable mesh methods of Douglas and Gallie, front fixing techniques arising from Landau's method, schemes based on the method of lines, weak solution approaches, and the use of the penalty parameter for the problem corresponding to the freezing index. Computational implications of variational inequality formulations are also being examined. This study will include finite difference and finite element techniques in two and three dimensions. Preliminary results indicate that front tracking methods are best for giving precise location of the moving boundary, but weak solution methods are easier to implement.

\section{STMRHASTIC ANALYSIS}

The development of efforts to apply and extend the coherentpotential approximation (CPA) for random substitutional alloys has followed two somewhat independent lines since the idea was first put forward in 1967 by Soven and Taylor. On the one hand there have been the more formal efforts looking for effective cluster type approximations, ${ }^{5}$ and finding a testing ground in simple models such as single 
band systems. On the other hand there have been many efforts to work with realistic models. For electronic properties, this started with Soven's use of a CPA-type approximation for muffin-tin potentials; this lead to various ways of calculating physical properties of real systems using an on-the-energy-shell multiple-scattering approach, but these methods did not.go beyond single-site approximations.

We have developed ${ }^{6}$ systematic multiple-scattering versions of the recent approximations due to Mills and Ratanavararaksa ${ }^{7}$ (MR) and Kaplan, Leath, Gray, and Dieh ${ }^{5}$ (KLGD) which incorporate two important effects not included in the CPA. These effects are cluster scattering and environmental disorder. Therefore, these approximations take us beyond the single-site averaging of the CPA and allow the muffin-tin potentials in the alloy to depend on the occupation of the surrounding sites. We have proved that cluster scattering is included in such a way as to preserve the necessary analytic properties of the approximation. These multiple-scattering versions of MR and KLGD permit calculations using on-the-energy-shell t-matrices in the spirit of the multiple scattering form of the CPA.

\section{REFERENCES}

${ }^{1}$ Solid State Division.

${ }^{2}$ Onio State University.

${ }^{3}$ V. Alexiades, A. D. Solomon, and D. G. Wilson, Modeling Binary Alloy Solidification Processes, ORNL/CSD-117 (1983).

${ }^{4}$ A. D. Solomon, "On Computing Methods for Moving Boundary Problems in Latent Heat Thermal Energy Storage,". Chapter IV in Latent Heat Storage Vol. 2, ed. G. Lane, Chemical Rubber Company Press, Boca Raton, Florida (to appear).

5T. Kaplan, P. L. Leath, L. J. Gray, and H. W. Diehl, "Self-Consistent Cluster Theory for Systems with Off-Diagonal Disorder," Phys. Rev. B, 21, 4230-4246 (1980). 
${ }^{6}$ R. Mills, L. 1. Gray, and T. Kaplan, "Analytic Approximation for Random Muffin-Tin Alloys," Phys. Rev. B, 27, 3252 (1983);

T. Kaplan and L. J. Gray, "A Self-Consistent Approximation for Muffin-Tin Models of Random Alloys with Environmental Disorder," Phys. Rev. B (submitted).

${ }^{7}$ R. Mills and P. Ratanavararaksa, "Analytic Approximation for Substitutional Alloys," Phys. Rev. B, 18, 5291-5308 (1978). 


\section{BIOMETRICS RESEARCH}
S. F. Ebey ${ }^{1}$
M. D. Morris
E. L. Froine
T. J. Mitchell
R. L. Schmoyer

\section{NONPARAMETRIC BIOASSAY}

Our research is continuing in dose-response curve estimation based on the assumption that the estimated curve is sigmoid. A sigmoid dose-response curve is nondecreasing and is convex at low doses but becomes concave at high doses. Suppose $n_{1}, \ldots, n_{k}$ "trials" are made at doses $x_{1}, \ldots, x_{k}$. Let $\left(p_{1}, \ldots, p_{k}\right)=p^{\prime}$ denote the probabilities of "death" at doses $x_{1}, \ldots, x_{k}$, respectively, and let $\left(\hat{p}_{1}, \ldots, \hat{p}_{k}\right)=\hat{p}^{\prime}$ denote the observed proportion of deaths. Let $\left(\tilde{p}_{1}, \ldots, \tilde{p}_{k}\right)=\tilde{p}^{\prime}$ denote the estimate of $\left(p_{1}, \ldots, p_{k}\right)$, constrained by the assumption of sigmoidicity. Finally, let $D$ be the $k x k$ diagonal matrix with $i-t h$ diagonal element $n_{j}\left(p_{j}\left(1-p_{j}\right)\right)^{-1}$. Based on the fact that $\left(p_{1}, \ldots, p_{k}\right)$ is asymptotically a $D$-weighted linear projection onto a hyperplane that contains $\left(\rho_{1}, \ldots, p_{k}\right)$, we have that asymptotically

$$
(\underline{\tilde{p}}-\underline{p})^{\prime} D(\underline{\tilde{p}}-\underline{p}) \leq(\underline{\hat{p}}-\underline{p})^{\prime} D(\underline{\hat{p}}-\underline{p}) \text {. }
$$

The above inequality, and its analog for similarly constrained estimators, is useful for establishing asymptotic confidence intervals and hypothesis tests, since the right-hand side of the fnequality is asymptotically a chi-square random variable. The asymptotic tests appear to be much inore powerful than previously derived tests which do not depend on asymptotic theory, but are based on rather severe approximations. The details of the above derivation have been suminarized in a manuscript. ${ }^{2}$

\section{A COMPUTER PROGRAM FOR THE ANALYSIS OF DISEASE PREVALENCE DATA}

Work has been completed on the description and extended documentation of a computer program for the statistical analysis of necropsy 
data arising from survival experiments (with perhaps some serial sacrifice) on populations of laboratory animals. Such experiments are common, for example, in the testing of potential risk factors, e.g., exposure to chemicals or radiation, for possible carcinogenic effects.

The methodology, which is based primarily on the use of log-linear models to express and test the assumptions of the investigator, has been previously described. ${ }^{3,4}$ The computer program and its use in estimating the model parameters and in testing hypotheses are described in a report. 5

\section{SAMPLE MEAN OF CORRELATED OBSERVATIONS}

Many biological investigations involve repeated observations often made on the same experimental unit. This frequently produces measurements which are statistically correlated. We have examined the precision of the unweighted sample mean under a model in which each measurement has the same population mean and variance, and the correlation between any two measurements is a positive constant raised to a power which is the absolute difference between measurement times. This model is the first order autoregressive model often used in time series analysis.

Our work is concerned with the design of such experiments when the sample mean is to be used as an estimator of the unknown common population mean. We first examined designs which consist of a number of equally spaced observations placed throughout a tixed time interval. The primary conclusion of this work is that there is an optimal finite sample size; if this sample size is exceeded, the standard error of the estimator actually. increases.

We are now considering the question of what spacing of observations is optimal. Given a time interval, a sample size, and a degree of correlation, we have characterized the optimal design in the sense of minimizing the standard error of the sample mean. In many applications, the degree of correlation is unknown. However, our results 
offer practical guidelines to aid in designing studies even when only a rough approximation of the correlation is available.

\section{RELATIVE RISK ESTIMATION USING POISSON REGRESSION MODELS}

Summarizing relative risk estimates across strata of a covariate is commonly done in comparative epidemiologic studies of incidence or mortality. A method for summarizing relative risk using previously developed Poisson rate analysis ${ }^{6}$ has been described and illustrated with examples of cancer incidence and mortality data. ${ }^{7}$ Under certain conditions poisson regression yields summary estimators that agreed closely with results obtained by conventional Mantel-Haenszel and rate standardization methods. An advantage of Poisson regression is its utility in modeling disease frequency, as demonstrated with examples of nonlinear models predicted by the multi-stage theory of carcinogenesis.

\section{MAXIMUM LIKELIHOOD ESTIMATION FOR CYTOGENETIC DOSE RESPONSE CURVES}

In vitro dose-response curves are used to describe the relation between the yield of dicentric chromosome aberrations and radiation dose for human lymphocytes. The dicentric yields follow the poisson distribution, and the expected yield depends on both the magnitude and the temporal distribution of the dose for low LET radiation. A general dose-response model that describes this relation has been obtained by Kellerer and Rossi using the theory of dual radiation action. The yield of elementary lesions is given by $k\left[\gamma d+g(t, \tau) d^{2}\right]$, where $t$ is the time and $d$ is dose. The coefficient of the $d^{2}$ term is determined by the recovery function and the temporal model of irradiation. Two special cases of practical interest are split-dose and continuous exposure experiments, and the resulting models are intrinsically nonlinear in the parameters. A general purpose maximum likelihood estimation procedure has been developed and illustrated with numerical examples from both experimental designs. ${ }^{8}$ Poisson regression analysis was used for estimation, hypothesis testing, and regression 
diagnostics. Results from the estimation procedure have been discussed in the context of exposure assessment procedures for both acute and chronic human radiation exposure.

\section{REFERENCES}

University of the South.

${ }^{2}$. L. Schmoyer, "Sigmoidally Constrained Maximum Likelihood Estimation in Quantal Bioassay," J. Amer. Stat. Assoc. (submitted).

${ }^{3} \ddot{B}$. W. Turnbull and T. J. Mitchell, "Exploratory Analysis of Disease Prevalence Data from Survival/Sacrifice Experiments," Biometrics $34,555-570$ (1978).

${ }^{4} T$. J. Mitchell and B. W. Turnbul1, "Log-linear Models in the Analysis of Disease Prevalence Data from Survival/Sacrifice Experiments," Biometrics 35, 221-234 (1979).

${ }^{5}$ T. J. Mitchell and B. W. Turnbul1, A Computer Program for the Statistical Analysis of Disease Prevalence Data from Survival/Sacrifice Experiments, ORNL/CSD-110, in preparation.

${ }^{6}$ E. L. Frome, "The Analysis of Rates Using Poisson Regression Models," Biometrics (to appear).

${ }^{7} E$. L. Frome and H. Checkoway, "Summary Estimators of Relative Risk Using Poisson Regression Models," A. J. Epidemiology (submitted).

${ }^{8}$ E. L. Frome and R. J. DuFrain, "Maxinum Likelihood Estimation for Cytogenetic Dose-Response Curves," Biometrics (submitted). 


\section{COMPUTATIONAL STATISTICS}

\author{
K. 0. Bowman \\ G. J. Davis \\ E. L. Frome \\ V. E. Kane 2 \\ T. J. Mitchell
}

\author{
M. D. Morris \\ N. J. Price \\ R. L. Schmoyer \\ L. R. Shenton ${ }^{3}$ \\ R. C. Ward
}

\section{COMPROMISE DESIGNS FOR ESTIMATION AND DETECTION OF LACK OF FIT}

Current computer algorithms for designing experiments are based on the assumption that the expectation $(n)$ of the response variable $(y)$ is related to $p$ design variables $x$ through the linear model:

$$
n={\underset{\sim}{\beta}}_{1}^{\prime} f_{1}(x)
$$

where ${\underset{\sim}{\beta}}_{1}$ is a $k_{1}$-vector of unknown coefficients and ${\underset{\sim}{f}}_{1}(\underset{\sim}{x})$ is a $k_{1}$-vector of known functions of $x$. The design criterion is usually a function of the $k_{1} \times k_{1}$ variance-covariance matrix of the least squares estimator $\hat{\beta}_{1}$. Such criteria focus on precise estimation of $\underline{\alpha}_{1}$, given that the model assumption (1) holds. Unfortunately, designs that are optimal with respect to these criteria are often virtually incapable of assessing the adequacy of the proposed model. Similarly, algorithms that focus only on the ability to detect lack of fit may not produce designs that are good for estimating $\beta_{1}$.

During the past year, we have continued research into the construction of "compromise designs," which are good with respect to both kinds of criteria (precise estimation and detection of lack of fit) without being optimal with respect to either. In order to take better advantage of existing algorithms for constructing "D-optimal" designs, we have changed the "precise estimation" criterion from the average variance of $\hat{\sim}_{-1}^{\hat{\beta}_{\alpha}} f_{1}(\underset{\sim}{x})$ as reported previously ${ }^{4}$ to the determinant of $\underline{M}=\sum_{i=1}^{n} \underset{\sim}{f}\left({\underset{\sim}{j}}_{j}\right) \mathfrak{f}_{\sim}^{\prime}\left({\underset{\sim}{\sim} j}_{j}\right)$, where ${\underset{\sim}{j}}_{j}, i=1,2, \ldots, n$, are the $n$ design points. The "lack of fit" criterion remains $C_{\ell}$, the average of the noncentrality parameter for testing the lack-of-fit of the model (1).

It is desirable to choose designs with large $C_{\ell}$ and $|\underset{\sim}{M}|$. We regard a design as inadmissible if there exists another design with 
criterion values $C_{\ell}^{*}$ and $|\underset{\sim}{M}|^{*}$ such that $C_{\ell}^{*} \geq C_{\ell}$ and $|\underset{\sim}{M}|^{*} \geq|\underset{\sim}{M}|$ with strict inequality for at least one criterion. It can be shown that any design that maximizes the mixed criterion

$$
C(\alpha)=(1-\alpha) \log |\underline{M}|+\alpha C_{\ell}
$$

for some $\alpha$ is admissible. We are currently modifying the algorithm DETMAX, which was designed to produce D-optimal designs, to construct designs that are optimal with respect to $C(\alpha)$. Some preliminary results have been obtained for a test case in which it is desired to select a fraction of a $2^{k}$ factorial design for presisely estimating the main effects while providing a good test for the presence of interactions.

Development of an alternative algorithm, based on the branch-andbound approach of Welch, is also under way. This will be applied to the mixed criterion (2) and also to the problem of generating all admissible designs for a given design problem.

\section{COMPROMISE DESIGNS FOR FACTORIAL EXPERIMENTS}

Morris and Mitche $11^{5}$ discussed a design optimality critarion, $\operatorname{tr}\left(L_{\sim}\right)$, for selecting experimental plans which provide relatively powerful tests for lack of fit in the proposed model. In the same report, a strategy for constructing "compromise" designs was described. This involves augmenting $\operatorname{tr}(\underset{\sim}{L})$-optimal designs with experimental runs which maximize the determinant of the information matrix for the assumed model (the object of D-optimality). These designs are intended to provide good properties for both estimation of parameters in the assumed model and detection of lack of fit.

We have recently constructed compromise designs for two-level factorial experiments, where the first order model is assumed. Designs which are $\operatorname{tr}(L)$-optimal for detecting lack of fit due to two-factor interactions were augmented using the computer program DETMAX. ${ }^{6}$ Designs were constructed for $k=3$ through 9 , and $n=k+2$ through $2 k+1$, where $k$ is the number of factors and $n$ is the number of 
experimental runs. These designs will be cataloged in an ORNL technical report to be published later this year.

\section{MINIMUM SIZE OF SEARCH DESIGNS}

Srivastava ${ }^{7}$ defined search linear models and designs, a special case of which is described as follows:

Let

$$
E(y)=\underset{\sim}{A} \underset{\sim}{B}, V(\underline{\sim})=\sigma^{2} \underset{\sim}{I}
$$

where $y$ is an n-element vector of observations, $A$ is a matrix of known constants determined by an experimental design, $\tilde{\sigma}^{2}$ is the known or unknown variance of each observation, and $\beta$ is a p-element vector of unknown parameters. We know that at most $\tilde{k}$ elements of $\underset{\sim}{\beta}$ are nonzero, but do not know which elements these are. The required search design must allow for simultaneous estimation of any $k$ elements of $\underset{\sim}{\beta}$. Srivastava showed that a necessary and sufficient condition for this estimation property is that every $2 k$ columns from $A$ be linearly independent.

We have shown that when all elements of $A$ are +1 or -1 (as with two-level factorial experiments), the number of runs in the experinental design (rows of $A$ ) must be at least $2 k+\log _{2}(p /(2 k-1))-1$. This bound is larger and, hence, more informative than Srivastava's bound of $2 k$ when $p$ is large relative to $k$.

\section{A GRAPHICAL INTERPRETATION OF STEIN'S PHENOMENON}

Computer graphics is a dramatically burgeoning nelw information medium. Two- and three-dimensional graphical displays of physical and mathematical phenomena now provide insights that were previously not readily obtained. In the present application, ${ }^{8}$ computer graphics are used to interpret a phenomenon, first pointed out by Stein, ${ }^{9}$ that the usual minimum variance unbiased (MVU) estinators of three or nore multivariate normal means are dominated in terıns of mean squared estimators by certain biased "shrinking" estimators. This shortconing of MVU estimators, along with the fact that it occurs in three or more, 
but not one or two, dimensions is perplexing. The theoretical arguments supporting it do not provide much intuitive insight into why it occurs.

After a simple reduction to a canonical problem, the way that shrinking estimators operate has been revealed in three-dimensional plots. Their effect has been shown to be detrimental along exactly one coordinate direction, but positive in the other coordinate directions. Further, these inferences did not depend on the dimension. Thus, it was demonstrated that as the dimension increases from one, the overall benefit of shrinking increases; and as the dimension changes from two to three, it becones positive.

\section{MAXIMUM LIKEL IHOOD ESTIMATOR OF GAMMA DISTRIBUTION}

A new conputer algorithm for the fast evaluation of the maximum likelinood estinators of the two-parameter gamma density was developed and documented. ${ }^{10}$ The method also lends itself well to the assessment of the higher monents of the estimators of the shape and scale parameters and their distributions.

\section{COMPUTATION OF THE, POLYGAMMA FUNCTIONS}

The psi (digamma) and polygamma functions are of ten used in conjunction with problems relating to the gamma probability density. ${ }^{10,11}$ Previously available programs ${ }^{12,13}$ for computing these functions are inadequate in some situations. We have developed and documented a more general program for this purpose.

\section{COMPUTERIZED FAA DI BRUNO'S FORMLA}

Let $z=G(y)$ and $y=f(x)$ be two functions such that all derivatives of $G(y)$ and $f(x)$ up to order $n$ exist. The usual formula for the nth derivative is given by Fá di Bruno as 


$$
\frac{d^{n} z}{d x^{n}}=\sum \frac{n !}{p_{1} ! p_{2} ! \ldots p_{n} !} \frac{d^{m} G}{d y} g_{k_{1}}^{p_{1}} g_{k_{2}}^{p_{2}} \ldots g_{k_{h}}^{p_{n}},
$$

where

$$
g_{s}=\frac{1}{s !} \frac{d^{s} f(x)}{d x^{s}},
$$

and the summation is over all partitions of $n$ such that

$$
\begin{gathered}
p_{1}+p_{2}+\ldots+p_{h}=m, \\
p_{1} k_{1}+p_{2} k_{2}+\ldots+p_{h} k_{h}=n .
\end{gathered}
$$

We now have a new notational approach which enables the formula to be computed avoiding the usual combinatorial summation.

The algorithm can be used in the derivation of explicit formulas for the cumulants of a probability distribution in terms of its moments and vice versa. It is also useful in the application of Taylor expansion methods to the approximation of the distributions of sample statistics, particularly for the Gamma and Weibull distributions.

\section{AN ALGORITHM FOR LINEAR DEPENDENCY ANALYSIS}

A FORTRAN code has been developed for performing Linear Dependency Analysis ${ }^{14}$ (LDA) on multivariate data. LDA provides a procedure for assessing the number of dependencies in the data and for computing competing dependency structures. Many of the disadvantages of using the classical approaches, such as principal component analysis and factor analysis, to study dependencies are eliminated in the LDA approach. Initial testing has indicated that LDA can provide data analysts with a powerful tool in assessing multivariate dependencies.

The portable code uses only stable orthogonal transformations throughout the algorithm ${ }^{15}$ and relies heavily on the known structure of the covariance matrix of variables containing linear dependencies. Competing dependencies are assessed by examining all possible subsets of predictor and estimated variables and eliminating computation, when possible, via a sequential deletion process. 
It should be emphasized that the LDA procedure is not generally intended to be a single-pass analysis. The code has different input and output options allowing the user to select those that are appropriate for a particular stage of analysis or state of prior knowledge.

\section{REFERENCES}

${ }^{1}$ Georgia State University.

${ }^{2}$ Fụ̂d Mútür Company.

University of Georgia.

" "Compromise Designs for Estimation and Detection of Lack of Fit," Mathematics and Statistics Research Department Progress Report, Period Ending June 30, 1982, 0RNL/CSD-105, pp. 10-11 (August 1982).

5M. D. Morris and T. J. Mitchell, Designs for the Detection of Inadequacy in Factorial Models, ORNL/CSD/TM-30 (1977).

${ }^{6}$ T. J. Mitchell, "An Algorithm for the Construction of 'D-Optimal' Experimental Designs," Technometrics, 16, 203-210 (1974).

7J. N. Srivastava, "Designs for Searching Nonnegligible Effects," pp. 507-519 (ed. J. N. Srivastava), A Survey of Statistical Dcsign and Lincar Modele, North-Holland Publishing Company, Amsterdam (1975).

${ }^{8}$ R. L. Schmoyer and N. J. Price, "A Graphical Interpretation of Stein's Phenomenon," Amer. Statist. (submitted).

${ }^{9} \mathrm{C}$. Stein, "Inadmissibility of the Usual Estimator for the Mean of a Multivariate Normal Distribution," Proceedings of the Third Berkeley Symposium on Mathematical Statistics and probab17tty, $1,197-206(1955)$.

${ }^{10}$ K. O. Bowman and $L$. R. Shenton, "Maximum Likelihood Estimators for the Gamma Distribution Revisited," Communications in Statistics, Series B (forthcoming).

${ }^{1 l_{K}}$. 0. Bowman and L. R. Shenton, "Properties of Estimators for the Gamma Distribution," Commun. Statist. Simula. Computa., 11(4) 377-519 (1982).

${ }^{12} \mathrm{~J}$. M. Bernardo, "Algorithm AS103 Psi (Digamma) Function," Applied Statistics 25, 315-317 (1976). 
13 B. E. Schneider, "Algorithm AS121 Triganma Function;" Applied Statistics 27, 97-99 (1978).

${ }^{14}$ V. E. Kane, R. C. Ward, and G. J. Davis, "Assessment of Linear Dependencies in Multivariate Data," JASA, submitted.

${ }^{15 R}$. C. Ward, G. J. Davis, and V. E. Kane, "An Algorithm for Linear Dependency Analysis of Multivariate Data," ACM Trans. Math. Software, submitted. 


\section{MATERIALS SCIENCE APPLICATIONS}

$$
\text { S.-J. Chang }{ }^{1} \text { S. M. Ohr }{ }^{2}
$$

\section{INCLINED PILEUP OF SCREW DISLOCATIONS AT THE CRACK IIP}

1. Without a Dislocation Free Zone. Inclined pileup of dislocations has been observed frequently in a transmission electron microscope. ${ }^{3,4}$ Its effect on the fracture of inetal has been the object of our study. The phenomenon of inclined pileup is modeled by a continuous distribution of screw dislocations in the pileup region. By considering the force balance at each dislocation due to the applied force, the friction force, and the forces due to other dislocations, a singular integral equation can be established for the distribution function of the screw dislocations. This integral equation has been solved by the Wiener-Hopf technique applied to the Mellin transform of the equation, and an analytical expression for the distribution function is thereby obtained. From this solution we have derived a simple form for the condition of finite stress at the end of the pileup zone, sometimes reterred to as the BCS or Dugdale condition, and for the total number of dislocations under the restriction of this condition. Numerical results from these two expressions imply that the energy required to generate an inclined pileup of screw dislocations does not vary significantly for $\phi$ in the range $-\pi / 3<\phi<\pi$, where $\phi$ is the angle of inclination from the plane of the crack. This result is consistent with observations.

2. With a Dislocation Free Zone. The inclined pileup of dislocations at the crack tip as observed in the transmission electron microscope frequently shows a dislocation free zone (DFZ) located between the crack tip and the region of the pileup. Linear pileup of screw dislocations for this case is modeled by an integral equation similar to that for the problem without a dislocation free zone. The integral equation has been solved by the extended Wiener-Hopf technique, a generalization of the Wiener-Hopf technique. The stress distributions 
within the DFZ and in the region outside the plastic zone are obtained in analytical forms. From this solution we derive expressions for the condition of finite stress at the end of the plastic zone, referred to as the DFZ condition, and for the total number of dislocations. Both of these results are generalizations of the BCS case in that they reduce to the corresponding result for the BCS case as the length of the dislocation free zone goes to zero. Numerical results indicate that the true stress intensity factor is approximately a function of the length of the DFZ and is not sensitive to the magnitude of the angle of inclination. The plastic zone size does not vary significantly for $\phi$ in the range $-\pi / 3<\phi<\pi / 3$.

\section{REFERENCES}

${ }^{1}$ Engineering Technology Division.

${ }^{2}$ Solid State Division.

${ }^{3}$ S.-J. Chang and S. M. Ohr, "Dislocation-Free Zone Model of Fracture," J. Appl. Phys. 52, 7174-81 (1981).

${ }^{4}$ S. M. Ohr and S.-J. Chang, "Dislocation-Free Zone Model of Fracture Comparison with Experiments," J. Appl. Phys. 53, 5645-51 (1982). 


\section{NUMERICAL LINEAR ALGEBRA}

$\begin{array}{ll}\text { R. E. Funderlic } & \text { E. } \mathrm{Ng}^{\mathrm{l}} \\ \text { J. A. George } & \text { R. J. Plemmons }{ }^{2} \\ \text { M. T. Heath } & \text { R. C. Ward } \\ \text { C. D. Meyer } & \end{array}$

\section{SPARSE LEAST SQUARES PROBLEMS}

Development continued on algorithms for solving sparse least squares problcms. Building on prcviously developed capabilities, 3,4 recent emphasis has been on increased generality in updating schemes and on condition number estimation. In addition to solving least squares problems by $Q R$ factorization, new algorithms have been developed for solving underdetermined linear systems by LQ factorization. This approach has been generalized to cope with underdetermined systems which are rank deficient, inconsistent, or require updating. A general survey of methods for sparse least squares problems was prepared for presentation at the 1982 Sparse Matrix Symposium. ${ }^{5}$

\section{THE FORCE METHOD FOR STRUCTURAL ANALYSIS}

Historically there are two principal methods of inatrix structural analysis, the displacement (or stiffness) method and the force (or flexibility) method. In recent times the force method has been used relatively little because the displacement method has been deemed easier to implement on digital computers, especially for large sparse systems. The force method has theoretical advantages, however, for multiple redesign problems or nonlinear elastic analysis because it allows the solution of modified problems without restarting the computation from the beginning. An implementation of the force method has been developed which is numerically stable and preserves sparsity. ${ }^{6}$ Although it is motivated by earlier elimination schemes, in our approach each of the two main phases of the force method is carried out 
using orthogonal factorization techniques recently developed for linear least squares problems.

\section{SPARSE MATRIX SOFTWARE CATALOG}

In order to provide a central clearinghouse of information on research in sparse matrix computations, a sparse matrix software catalog was prepared for distribution at the Sparse Matrix Symposium held on October 24-27, 1982, in Fairfield Glade, Tennessee. Most major areas of sparse matrix computations are represented in the catalog, including operations on sparse matrices, systems of linear equations, least squares, eigenvalues, optimization, ordinary and partial differential equations, and selected applications. For each software package, the catalog contains information on the problem domain to which the software is applicable, method of solution, language and portability details, references to documentation, and a contact for furtiner information or acquiring the software. The collecting, collating, and reporting of this information were accomplished by means of a form which was circulated among researchers in this field.

\section{COMPUTATIONAL METHODS FOR SINGULAR IRREDUCIBLE M-MATRICES}

Markov queuing networks give rise to very large, sparse, irreducible, siriyular (zero culumn sums) M-matrices A. The stationary probability distribution vector is the solution to a homogeneous system of linear equations $A x=0$. Certain economic, petroleum reservoir, compartmental, and discrete Neumann problems give rise to related systems. The splitting $A=M-N$ with the matrix M having symmetric zero struc-

ture has been shown to be a regular splitting. ${ }^{7}$ A sparse LU factorization of a symmetric permutation of $M$ can be obtained using a standard symmetric ordering such as minimum degree, and pivoting for stability is unnecessary. Splitting strategies including those that have the larger elements of $A$ in $M$ have been compared. Sensitivity of the solution vector $x$ is being studied, and updating methods for these systems are being investigated. 


\section{REFERENCES}

IUniversity of Waterloo.

${ }^{2}$ North Carolina State University.

${ }^{3}$ A. George and M. T. Heath, "Solution of Sparse Linear Least Squares Problems Using Givens Rotations," Linear Algebra Appl. 34, 69-83 (1980).

${ }^{4}$ M. T. Heath, "Some Extensions of an Algorithrn for Sparse Linear Least Squares Problems," SIAM J. Sci. Stat. Comput. 3, 223-237 (1982).

5M. T. Heath, Numerical Methods for Large Sparse Linear Least Squares Problems, ORNL/CSD-114 (April 1983) and SIAM J. Sci. Stat. Comput. Tforthcoming).

${ }^{6}$ M. T. Heath, R. J. Pleminons, and R. C. Ward, Sparse Orthogonal Schemes for Structural Optimization Using the Force Method, ORNL/CSD-119 May (1983).

TR. E. Funderlic and R. J. Plemmons, A Combined Direct-Iterative Method for Certain M-Matrix Linear Systems, ORNL/CSD-112 (February 1983) and SIAM J. ATgebraic Discrete Meth. (forthcoming). 


\section{RISK ANALYSIS}
D. Downing ${ }^{1}$
R. Piziak ${ }^{3}$
W. Kuo ${ }^{2}$
V.R.R. Uppuluri

\section{MAN AND MACHINE: PROBABILISTIC LEARNING MODELS}

Parvin and Grammas ${ }^{4}$ developed a learning model which has man and machine as input factors in a learning process. They presented a mathematical model in which they assumed the probability that a machine operator makes an error changes from trial to trial. In particular, the probability that the person makes an error at the $n^{\text {th }}$ trial was assumed to be $1 /(n+1)$. They studied the random variable $S$, the number of errors made in a fixed number of trials, and gave an expression for the mean value of $S$. These results were extended to learning models with arbitrary choice of probabilities from trial to trial. At this level of generality, expressions were obtained for the mean and variance of $S$ and some distributional properties of $S$ were also derived. The probability distribution of $S$ was shown to satisfy a recursive relation which led to interesting connections with results found in combinatorial theory.

Consider a sequence of independent Bernoulli trials $\left\{x_{n}: n=1,2, \ldots\right\}$, where $x_{n}=1$ denotes a success and $x_{n}=0$ denotes a failure. In the context of the learning model $p_{n}$ denotes the probability that no error is made on the $n^{\text {th }}$ execution of the task, and

$$
p_{n}=p\left[x_{n}=1\right]=1-q_{n}=1-p\left[x_{n}=0\right] \text {. }
$$

Let $S_{n}$ denote the number of "successes" (i.e., the number of error-free executions of the task) in the first $n$ trials. It is well known that the mean and variance of $S_{n}$ are given by

$$
\begin{aligned}
E\left(S_{n}\right) & =p_{1}+p_{2}+\ldots+p_{n}, \\
\text { and } \operatorname{Var}\left(S_{n}\right) & =p_{1} q_{1}+\ldots+p_{n} q_{n} \text {. }
\end{aligned}
$$

In general, it is not possible to give an expression for the probability density function for $S_{n}$, denoted by $P\left[S_{n}=k\right]$ for 
$k=0,1,2 \ldots, n$. However, the following recursive relation can easily be verified:

$$
P\left[S_{n+1}=k\right]=q_{n+1} P\left[S_{n}=k\right]+p_{n+1} P\left[S_{n}=k-1\right]
$$

Let

$$
R(n, k)=\frac{p\left[S_{n}=k\right]}{P\left[S_{n}=0\right]}=\frac{p\left[S_{n}=k\right]}{q_{1} q_{2} \ldots q_{n}}
$$

and the "odds ratio"

$$
\beta_{n}=p_{n} / q_{n}
$$

The recursivè rèlation (4) becomes

$$
R(n+1, k)=R(n, k)+R_{n+1} R(n, k-1)
$$

with the boundary conditions

$$
\begin{aligned}
& R(n, 0)=1 \\
& R(n, n)=\beta_{1} \beta_{2} \ldots B_{n} .
\end{aligned}
$$

Using the odds ratios, one can construct a table of values of $R(n, k)$ based on (7). More interestingly, given a sequence of odds ratios $\left\{\beta_{n}\right\}$ and the recursion (7), one can construct a general learning model by taking

$$
P\left[S_{n}=k\right]=R(n, k) / \prod_{j=1}^{n}\left(1+\beta_{j}\right) .
$$

The special case $p_{j}=i /(i+1)$ and $q_{j}=1 /(i+1)$ gives the model considered by Parvin and Grammas. ${ }^{4}$ For this case $\beta_{n}=n$ and (7) becomes

$$
R(n+1, k)=R(n, k)+(n+1) R(n, k-1)
$$

which is the recursion satisfied by Stirling Numbers of the First kind.

Further details may be found in a forthcoming paper. 5

\section{PROPAGATION OF UNCERTAINTIES}

In the context of propagation of uncertainties in a system, $x_{1}, x_{2}, \ldots, x_{n}$ are considered to be the input variables characterizing the components of a system. The output variable $y=f\left(x_{1}, x_{2}, \ldots, x_{n}\right)$ may be defined by a computer algorithm as opposed to an analytical 
expression. The problem of the propagation of uncertainties is the problem of finding the uncertainty in the output variable for given uncertainties in the input variables.

The methodology for performing an uncertainty analysis in complicated systems is still under development. Many of the methods in use today are based on computer codes and have been used successfully in radiation pathway problems, probabilistic risk assessment, nuclear safety, and related areas. Important contributions have been made in the following topics: (1) screening of variables by using methods such as adjoint techniques; (2) finding approximating functions for the output by using the techniques of response surface methodology; (3) finding the distributional properties of this approximating function either exactly or by using Monte Carlo or Latin hypercube sampling methods; and (4) aggregating these aspects in applications. Pitfalls in the above procedures have been identified and discussed in review papers. 6,7

\section{REFERENCES}

ITechnical Applications.

${ }^{2}$ Bell Telephone Laboratories, Holmdel, New Jersey.

${ }^{3}$ Baylor University.

4M. Parvin and G. W. Grammas, "Man and Machine: On a Probabilistic Learning Model," Policy Analysis and Information Systems 4, 47-51 (March 1980).

5V. R. R. Uppuluri and R. Piziak, "General Probabilistic Learning Models,". Policy and Information (to appear in 1983).

${ }^{6}$ D. J. Downing and V. R. R. Uppuluri, "Propagation of Uncertainties: An Overview," pp. 173-192 in Proceedings of the 1982 DOE Statistical Symposium, October 13-15, 1982, EG\&G Idahos Inc., Idaho Fal1s, Conf-821021.

7V. R. R. Uppuluri and W. Kuo, Survey of Error Propagation in Systems, NUREG/CR-2839, ORNL/CSD/TM-190 (April 1983). 
PART B. STATISTICAL AND MATHEMATICAL COLLABORATION

\section{BIOLOGICAL SCIENCES}

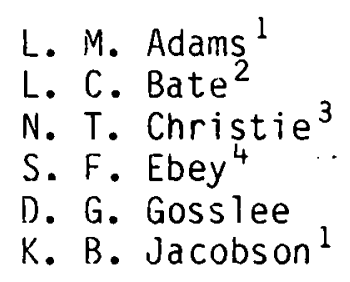

S. J. Kennel ${ }^{1}$
S. Lock
T. J. Mitchell
E. F. Oakberg
R. L. Schmoyer
J. B. Storer
R. L. Ulirich

DIESEL FUEL AEROSOLS

Results from "Phase II", an incomplete block experiment to assess the effect of diesel fuel aerosol "smoke" screens on rats, have been analyzed. Factors, dose $(0,8$, or $12 \mathrm{mg}-\mathrm{hr} / \mathrm{liter}$ ), time of exposure (2 or 6 hours), and frequency ( 1 time/week for 9 weeks or 3 times per week. for 3 weeks) were, for logistical reasons, necessarily confounded into three blocks of four runs each. The design of the experinent admitted unbiased estimation of main and second-order effects. Significant and important changes with dose were seen in body weights and in the amount and types of pulmonary free cells.

The Phase II experinent served as a pilot study for Phase III, a 25-week experiment run with 27 exposures at doses $0, .25, .75$, and 1.5 $\mathrm{mg}-\mathrm{hr} / \mathrm{liter}$. The 27 exposures were given during the first 14 weeks, with the remaining time used to assess recovery. Endpoints included body weights, food consumption, pulmonary free cells, tissue weights, 
pulmonary functions, startle reflex, and a battery of clinical chemistry tests. Each of the four dose groups, including the dose-0 controls, were loaded into aerosol chambers to receive the treatments. To assess the effect of loading, an unloaded control group was also included for many endpoints.

The data from Phase III are now being analyzed. Since Phase III represents exposures both more chronic and at lower doses than those in Phase II, observed effects are likely to be more subtle. Nevertheless, the treatment appears to have a clear effect on several endpoints, especially body weights.

\section{BINDING OF MONOCLONAL ANTIBODY TO TUMOR CELLS}

Monoclonal antibodies are used for immunoassays and radioimaging of primary and metastatic tumors. These functions require efficient binding of antibody to cell surface antigen. To assay for direct binding of radiolabeled antibody to viable cells, antibody diluted in growth medium was incuhated with tumor cells. In each experiment a series of successive incubations was performed and the amount of antibody bound in each incuhatiton was recurded. If thc (unknown) fraction $\theta$ of antibody bound is the same for each incubation, then it can be shuwi that

$$
Y=\ln [A b \text { bound }]=X \text { ln }(1-\theta)+\ln [n \theta /(1-\theta)]
$$

where $X$ is the incubation number and $n$ is the (unknown) total active antibody. This model was fitted to the data as a linear regression of $Y$ vs $X$; estimates of $n$ and $\theta$ were then derived frum the estimates or the slope and intercept of the regression line.

\section{RELATIVE BIOLOGICAL EFFICIENCY (RBE) OF FISSION NEUTRONS AT LOW DOSES FOR LIFE SHORTENING IN MICE}

We have analyzed recently published data on the effects of low doses of fission neutrons on the mean survival times of mice. The analysis for single dose exposures was confined to doses of 20 rad or less, while for fractionated exposures only total doses of 80 rad or less were considered. We used the well known power function model, 
life shortening $=B D^{\lambda}$ where $D$ is the radiation dose, to fit the single exposure data. Under the assumption that the life shortening effects from each of a series of exposures are additive, the expected life shortening for fractionated exposures is then $B D^{\lambda} n^{1-\lambda}$, where $n$ is the number of fractions. By comparing the observed life shortening for the fractionated exposures with that predicted using the values of $\beta$ and $\lambda$ estimated from the single exposures, we were able to show that at low doses per fraction, either 1) the effects are not additive or 2) $\lambda>0.9$. Analysis of the data for gamma rays showed that an exponent of 1.0 gave an acceptable fit. Taken together, these findings indicate that the RBE for neutrons cannot change more rapidly with neutron dose than about $R B E_{N} \cong k / D_{N}^{0.1}$, where $k$ depends on strain and sex. This conflicts with the more widely accepted relationship, $R B E_{N} \cong k / D_{N}^{0.5}$.

\section{CELL TRANSPLANTATION BIOASSAY}

In a cell transplantation assay experiment, conducted in the Biology Division of ORNL, cells are injected into host mice at two sites per mouse. The number of sites giving rise to colonies after injection of irradiated cells relative to that after injection of nonirradiated control cells is a measure of the viability of the irradiated cells. As reported previously ${ }^{5}$, a statistical procedure was developed to estimate the $D_{50}$, i.e., the cell dose which gives rise to colonies at $50 \%$ of the sites, for irradiated cells relative to the $D_{50}$ for unirradiated control cells.

These estimates of $D_{50}$ have now been used to express the relationship between cell viability and radiation dose by fitting the model

$$
\frac{D_{50}(0)}{D_{50}(x)}=1-\left[1-\exp \left(-x / x_{0}\right)\right]^{N}
$$

where $X$ is the radiation dose, and $N$ and $X_{0}$ are parameters to be estimated by the fitting procedure. 
Two experiments were analyzed: (1) injection 24 hours after exposure, and (2) immediate injection. In each experiment the doses were $0,100,300,600,900$ and 1200 rads. Fitting was done by weighted nonlinear least squares using the SAS procedure NLIN. A chi-square statistic based on the residual sum of squares was used to test the fit of the model. The fit was good for experiment (2) but not for experiment (1).. For experiment (2), an approximate $95 \%$ confidence region for the parameters $N$ and $X_{0}$ was also obtained.

\section{LEVELS OF SIGNIFICANCE OF TESTS ON SMALL PROPORTIONS}

The research on statistical tests for potential mutagens ${ }^{6}$ was continued by investigating levels of significance for several methods to test the difference between proportions. In the context of sample size estimation and the power of tests, the discrepancy between nominal and actual levels of significance is important and especially important when the proportions are small. For $N p<1$ the tests are generally conservative with large differences in degree among the tests. For example, for $N p=0.46, N>50$ and a nominal level of 0.05 , the actual level of signiticance for the angular transformation test is 0.05 while for Fisher's exact test it is approxinately 0.0001. Levels of significance using the Freeman-Tukey transformation and the chi-test were also investigated. A preliminary investigation on sample size estimation and the power of these tests was also completed.

Computer programs have been written in FORTRAN for the POP-10 to calculate the level of significance, the power and the required sample size for each of the methods of testing proportions. These programs, which are well documented, produce tables as specified by input parameters.

\section{TOXICITY OF METAL IONS}

Multivariable analyses of the toxicity of metal ions are under way to identify those properties of metal ions which are correlated with toxicity. The new statistical methods of regression diagnostics are 
being used to develop models which correlate well with LD50s in mice ' and LC50s in Drosophila. ${ }^{7}$ Eleven, of over 30, properties have been studied resulting in the selection of four properties which jointly increase the correlation coefficient markedly as compared with the largest correlation between toxicity and any single property. The regression diagnostic methods of analyzing multi-collinearity are important in variable selection. Their use increases the likelihood of excluding variables which may improve the model only because of an outlier or other nonrepeatable peculiarity of the data. In this manner, several properties will be selected from the entire set. In addition, diagnostics will be applied to the regression for each. response on these few variables to investigate the influence of each of the metal ions.

\section{CIRCADIAN RHYTHM IN MITOTIC CELL FREQUENCIES}

In order to plan experiments that will yield objective data on the effect of radiation on the cell-cycle properties of spermatogonial stem cells, the possibility that spermatogonial stem cells may have a circadian rhythm must be considered. A recent experiment determined the mitotic index throughout the 24 -hour period. ${ }^{8}$ Statistical tests of significance indicated that the diurnal variation was random, so that future experiments can be planned under the assumption that the mitotic index is unaffected by time of day.

The statistical analyses tested and accounted for variation among animals and stages of cell growth. Chi-square tests, nonparametric tests and tests based on circular distributions all indicated that the variation in mitotic index among different times of day was not significant and could be considered to be random.

\section{REFERENCES}

${ }^{1}$ Biology Division.

${ }^{2}$ Analytic Chemistry Division. 
3University of Texas Medical School.

${ }^{4}$ University of the South Sewanee.

${ }^{5}$ Mathematics and Statistics Research Department Progress Report, Period Ending June 30,1982 , ORNL/CSD-105, p. 38 (August 1982).

"Sample Size Estimation for Tests on Potential Mutagens," Mathematics and Statistics Research Department Progress Report, Period Ending June 30, 1982, 0RNL/CSD-105, p. 44 (August 1982).

${ }^{7}$ N. T. Christie, D. G. Gosslee, L. C. Bate and K. B. Jacobson, "Quantitative Aspects of Metal Ion Content and Toxicity in Drosophila," Toxicology (to appear).

${ }^{8}$ E. F. Oakberg and C. D. Crosthwait, "A Test for a Circadian Rhythm in Mitotic Activity of Spermatogonial Stem Cells," Biology Uivision Progress Report, Period Ending July 31, 1982, OR $\overline{N L-5927, ~ p p . ~ 133-~}$ 134 (December 1982). 


\section{ENERGY}
J. D. Birdwe $11^{1}$
R. W. Heller
D. Flanagañ
M. Griffey ${ }^{3}$
A. J. Laub4
W. Meroney
M. T. Heath
R. W. Rochelle
A. Shor ${ }^{2}$
H. Tsao
T. Wright

SOFTWARE FOR COMPUTER-AIDED CONTROL SYSTEM DESIGN

The objective of this project is to specify the requirements for a computer software package for computer-aided control system design (CACSD). The package is to have the capability to solve control and estimation problems in the design, modeling, and analysis of dynamic systems. The package is to organize existing results into a unified body of software which will furnish a standardized set of tools and services and allow long-term maintenance and growth. Although it is primarily intended to provide the electric utility industry with the conceptual tools needed for the planning, engineering, and operation of the electric energy systems of the future, it will be equally applicable to many other areas. The issues addressed in the current study include selecting the programming language to be used and the algorithms to be included, assessing the impact of potential applications and future hardware, establishing coding standards, and determining needed support of graphics and software tools.

\section{DEVELOPMENT OF THE ENERGY INFORMATION ADMINISTRATION (EIA) SAMPLING FRAME OF DISTILLATE AND RESIDUAL FUEL OIL DEALERS (EIA-764)}

The EIA-402 Fuel 0il Identification Survey was conducted in the fall of 1979 for the purpose of identifying all marketers of either No. 2 Dist1llate Fuel or No. 6 Residual Fuel. This EIA-402 sampling frame had no method of updating auxiliary information or of adding new companies.

EIA was developing a consolidated Petroleum Product Sales Report Survey that would require a current 11st of No. 2 distillate fuel oil 
marketers. Therefore, it was necessary to replace the EIA-402 sampling frame with a more current listing that could be used to select samples for the Petroleum Product Sales Report as well as other surveys for which the EIA-402 served as the sampling frame. A major project was undertaken to update and reconstruct the EIA-402. The new form is called the EIA-764 Sampling Frame of Distillate and Residual Fuel 0il Dealers.. The project involved a huge mailout to over 56,000 companies from Dun's Marketing List; SIC Codes 5171, 5172, and 5173; various state and industry lists; yellow pages; and 11 EIA frames (including the EIA-402) in an effort to update information and to identify new potential respondents. Follow-up systems programilny, Udad prucessilly, and file cleanup procedures were necessary.

After a clean file was produced, an evaluation of the coverage of the target population by the EIA-764 was attempted. Suggestions were made to assist in the coverage evaluation. A report ${ }^{6}$ was produced which gives a review of the statistical literature on frames. A short paper $^{7}$ was also produced which gives some simple properties of a simple random sample which are not well known.

\section{SAMPLING PLAN FOR FORM EIA-61A SYSTEM ASSESSMENT}

A sampling plan was developed to assess the EIA-64A survey (Annual Report of the Origin of Natural Gas Liquids Production) which provides the basis for the DOE annual estimation of U.S. proved reserves of natural gas liquids and dry natural gas. The ElA-64A system assessinent was conducted to 1) assess the validity, meaningfulness, and accuracy of the data submitted on Forin EIA-64A; 2) review and assess the EIA-64A frame and frame maintenance procedures; 3 ) identify specific issues and problems with the EIA-64A system and assess their significance;

4) recommend potential system modifications, as appropriate; and

5) recommend caveats for alerting users to limitations of the data produced by the system, as appropriate. 


\section{REFERENCES}

IUniversity of Tennessee.

Energy Division.

${ }^{3}$ Energy Information Administration.

${ }^{4}$ University of Southern California.

${ }^{5}$ Evaluation Research Corporation, Vienna, Virginia.

${ }^{6} \mathrm{~T}$. Wright and H. J. Tsao (1982), "A Frame on Frames: An Annotated Bibliography," Presented at the Small Conference on the Improvement of the Quality of Data Collected by Data Collection Systems, November 11-12, 1982, Oak Ridge, Tennessee.

${ }^{7}$ T. Wright and H. J. Tsao (1983), "Some Useful Results on Simple Random Sampling" (submitted for publication). 


\section{ENGINEERING}
L. A. Abbatiellol
L. J. Gray
D. A. Adams ${ }^{2}$
S. E. Groothuis 5
C. A. Serbin
J. Barhen ${ }^{3}$
K. 0. Bowman
G. DeSaussure ${ }^{3}$
D. Dietrich ${ }_{4}^{1}$
G. $\mathrm{Hall} l^{6}$
W. Hame ${ }^{7}$
E. Leach
J. Mart in ${ }^{8}$
J. A. Euler ${ }^{4}$
L. Martin 7
A. D. Sol omon
R. E. Funderlic
N. J. Price
F. H. Speckhart ${ }^{4}$
M. L. Stephens ${ }^{9}$
$P$. K. Stuber ${ }^{9}$
J. Toml inson 8
C. Weisbin ${ }^{3}$

\section{PLATING AND ELECTROCIIIMICAL MACIIINING}

The development ${ }^{10}$ of a computer code co simulate a two-dlmens lum 1 electrochemical machining (ECM) process is nearing completion. This code uses the NAG subroutine DO3EAF to solve for the current densities on the tool and workpiece surfaces. A simple iteration process is then used to solve for the polarization on each electrode. After cutting, smoothing routines are then used to produce the new workpiece surface.

Calculations for a rectangular shaped insulated tool are now being performed. The results will be compared to experiments run on the $\mathrm{y}-12$ Chemform machine.

\section{LATENT-HEAT THERMAL ENERGY STORAGE}

During the reporting period, collaboration with the Latent Heat Thermal Energy Storage efforts centered upon the further development of a computer simulation of passive solar heating of a building with contained phase change material (PCM). The purpose of the simulation program is to serve as a tool for addressing the question of what benefits, if any, are to be derived from the incorporation of a PCM in a passive solar building structure. Such questions include a) where is the PCM to be placed, b) what is the "optimal" melting temperature of the PCM, and c) what are the critical factors and dimensionless parameters determining the behavior of the overall system. In its 
present state of development, the code is a flexible tool containing the following elements: a) beam and diffuse radiation from the sun, with time varying incidence, azimuth and altitude angles; b) PCM contained in either layers attached to the interior wall surfaces or placed in an interior "curtain" wall; c) walls consisting of variable numbers of layers of materials through which heat passes by pure conduction; d) convective heat transfer between the room air and the exterior wall surfaces; e) cross radiation between interior wall surfaces; and f) a "comfort" temperature consisting of a weighted average of room air temperature and interior surface temperatures. Results obtained thus far can be summarized as follows:

A) There is a sizable difference between simulation results obtained when wall sections are represented by lumped "resistance" circuits and when heat is transferred via pure conduction which is modeled using finite differences.

B) The chief effects of PCM inclusion are felt in moderating the high temperatures ordinarily experienced in passive solar structures.

c) There is sizable sensitivity to the choice of such components as the absorptivity of the exterior surfaces.

D) For our model and the cases run thus far, a PCM melt temperature of about $70^{\circ} \mathrm{F}$ would appear to be "optimal" in some sense.

In parallel with the further development of the computer simulation, we have performed some numerical experiments aimed at developing dll "intelligence" and "learning" capability for the reduction of computing time. We hope to be able to report more extensively on these attempts in the report of next year's progress.

\section{ROTOR FORCED RESPONSE, NATURAL FREQUENCIES, BALANCING}

"CYLINDER", a rotor dynamics program, was introduced in a previous annual report. 11 Several options have been added in such a way as not to require modification of established data sets. Users who have knowledge and need of the new options may specify logical variables in the input; the default mode of operation is as before. The new options include deflection plotting, noninteger or nonincremental speeds, 
flexibility of imperfection input, and a variable grid discretization. The latter allows CYLINDER to more easily specify rotors of different sizes for stacked cases. In addition modifications are being made to CYLINDER which provide for more robust convergence to natural frequencies.

From CYLINDER the programs SIMCYL and INCYL have evolved. ${ }^{12}$ SIMCYL has been used to simulate rotor imperfections and from these to provide test deflections for INCYL to attempt to calculate the contrived given imperfections. Recently SIMCYL has been separated from INCYL so as to use laboratory deflection data from which sharp localized imperfections are expected. As INCYL has evolved from an experimental, frequently modified program to a production program, run procedures have become more streamlined. This allows better interfacing between laboratory deflection data and processing of output imperfections on the Separation Systems Division's PDP-11.

As reported in the previous annual report, ${ }^{13}$ software has been developed for rotor dynamics problems based on modified quadratic eigenvalue problems. This work and associated stability problems have been documented in a Separation Systems Division report. Recently equations have been derived and programs written for several new qeometries.

\section{DEVELOPMENT OF "INTELLIGENT" ROBOTIC DEVICES}

The aim of this collaborative effort is to aid in the establishment of a national center for research into intelligent robotic devices. The approach used has been to establish an "hierarchical" structure for robotic thinking and strategy forimulation. The nighest level, or "organizational" level, is devoted to the highest level of thought, while the lowest, or "machine" level, is devoted to mechanical manipulation of joints. The immediate application of the results of research will be to the robotic devices involved in the fuel recycle progran of ORNL. Our effort has been aimed at the development and understanding of the "real world" model and its interaction with strategy development. 
CONFIDENCE LIMITS FOR THE EXPECTATION OF A POISSON VARIATE

The technical report "Confidence Intervals for the Expectation of a Poisson Variate" (ORNL/CSO-115), which presents confidence limits on a Poisson variate and the smallest alternate mean which can be detected with specified probability, has been published. Existing studies in the literature consider the problem of testing whether the counts from a uranium source are zero. This condition is too stringent in most cases allowing only a small amount of uranium to be present before setting off the alarm. The new procedure will permit experiments to assume the presence of a uranium source and assume (or define) the levels of counts of the uranium source. Many problems exist in finding confidence limits of a Poisson variable, and results from this report should be applicable in numerous other studies.

\section{REFERENCES}

${ }^{1}{ }_{Y-12}$ Development Division.

${ }^{2}$ Separation Systems Division.

${ }^{3}$ Engineering Physics Division.

${ }^{4}$ University of Tennessee at Knoxville.

${ }^{6}$ Millsaps College, Jackson, Mississippi.

7 Instruments and Controls Division.

${ }^{8}$ Engineering Division.

${ }^{9}$ Co-op Student, Tennessee Technological University. 
44

10 Mathematics and Statistics Research Department Progress Report, Period Ending June 30, 1982, ORNL/CSD-105 (August-1982).

${ }^{1 l_{R}}$. E. Funderlic, "Mode Shape Analysis and Centrifuge Rotor Response to Balance Weights," Mathematics and Statistics Research Departmont Progress Report, Period Ending June 30, 1980, ORNL/CSD-61, p. 29 (September 1980).

${ }^{12}$ R. E. Funderlic, "Centrifuge Forced Response, Mode Shapes, Balancing," Mathematics and Statistics Research Department Progress Report, Period Ending June 30, 1981, 0RNL/CSD-82, p. 29 (September 1981).

${ }^{13}$ Mathematics and Statistics Research Department Progress Report, Period Ending June 30, 1982, 0RNL/CSD-105, p. 54 (August 1982). 


\section{ENVIRONMENTAL SCIENCES}

$\begin{array}{lll}\text { L. W. Barnthouse } & \text { J. J. Elserl } & \text { M. D. Morris } \\ \text { J. J. Beauchamp } & \text { P. J. Francol } & \text { A. Rosen } \\ \text { J. E. Breck } & \text { J. M. Giddings } & \text { R. L. Schmoyer } \\ \text { R. M. Cushman } & \text { B. L. Kimmel } & \text { M. H. Wolfe } \\ \text { S. F. Ebey } & \text { R. Merchant } & \end{array}$

\section{EFFECTS OF COAL-DERIVED OIL ON A FRESHWATER ECOSYSTEM}

Single species bioassays are useful for indicating relative toxicities of chemical contaminants but are too simple to estimate ecosystem-level responses to environinental exposure. Microcosms, however, mimic general properties of whole ecosystems and provide a model for evaluation of toxicant effects in a natural context. In this study, 16 freshwater pond microcosms (76-l) were established in the laboratory in order to determine the effects of chronic coal-oil releases on an intact aquatic ecosystem. Experimental factors were (1) rate of oil application with seven levels plus a control, and (2) frequency of oil application with two levels, daily and weekly. Each microcosm was randomly associated with a combination of the two factors.

Responses examined included water chemistry (e.g., water $\mathrm{pH}$ and conductivity), ecosystem metabolism, and community structure. The data used in the analysis consisted of eight weekly observations on the water $\mathrm{pH}$ and conductivity responses from each microcosm. Weekly pretreatment values were also available from each microcosm. Because of the lack of replication, except for the control microcosm, the pretreatment mean for each microcosm was subtracted from its observed responses during the treatment period to eliminate the microcosm differences that might exist. These adjusted responses became the input for the subsequent analysis. Associated with each experimental unit, or microcosm, was an observation vector of the weekly response values for the treatment period. 
The presence of a significant effect associated with frequency of oil application was examined by using multivariate regression analysis on the difference between the corresponding observations from daily and weekly dosed microcosms with the same rate of oil application. The multivariate regression analysis indicated that frequency of application had no significant effect. Therefore, this factor was ignored in the subsequent analysis and microcosms within a treatment group were considered as replicates.

With the gain of replication, it was possible to test for significant dose effects by applying the growth curve concepts developed by Grizzle and Allen. ${ }^{4}$ In this final analysis a quadratic function of time was used to describe the responses for each treatment group. The resulting estimated parameters for the response curves were then used to test for significant dose effects. The same estinated paraneters were used as input to a canonical analysis to graphically display the similarities and differences of the treatment groups. This analysis has been useful in determining those responses that can be significantly affected by chronic coal-oil releases, and it will provide information for comparisons with analogous experiments in outdoor ponds.

\section{INFLUENCE OF STEMFLOW ON THE DISTRIBUTION OF SUIL SULFATE}

Stemflow influence on soil sulfate and pH distribution near the base of two tree species (red maple and scarlet oak) was studied at two watersheds located in the Cumberland Plateau region of Tennessee. The soil profile around the base of each sampled tree was sampled at four specified distances from the base along four transects (upslope, downslope, and two transects perpendicular to the upslope-downslope transects). Trees from three different size classes for each species were sampled to evaluate the effect of tree size on the responses of soil sulfate and $\mathrm{pH}$.

The experimental factors to be evaluated were (1) site at two levels, (2) tree species at two levels, (3) tree size at three levels 
within species, (4) transect within tree at four levels, and (5) distance along transect at four levels. A total of 12 trees was sampled, one for each combination of factors (1)-(3). All of the information about factors (1)-(3) could be evaluated through an analysis of 12 means, one from each tree, because of the balance with respect to the remaining factors (4) and (5). An evaluation of factors (4) and (5) was accomplished by a pooling of the analysis of the observations for each individual tree.

In order to have some degrees of freedom left for testing the effects of transects within trees as well as distances within transects, a simplyfying assumption was made. This assumption considered the two transects perpendicular to the upslope-downslope transects as replicates and was reasonable since the primary movement of sulfate would be determined by the upslope-downslope gradient rather than the perpendicular gradient. This simplification also made it possible to test for significant transect and distance effects. Although the lack of replication made it difficult to associate any site differences with any particular factor such as sulfate input, which differed between the two sites, the results of this analysis will be helpful in designing future studies.

\section{EFFECT OF PETROLEUM AND SYNTHETIC OILS ON REPRODUCTION OF THE MILKWEED BUG}

A laboratory study has been conducted to demonstrate the effects, if any, of two coal-derived synthetic oils and petroleum on reproduction of the large milkweed bug. A deleterious effect could have an impact at the population level. The experinent involved exposing replicate palrs of adult male and female bugs to predetermined doses of the substances of interest. and recording for a three-week period the number of eggs laid each day. The observations from each replication were averaged to produce an estimate of the number of eggs laid per day

over the three-week period.

An examination of the replicate fecundity observations for each substance as a function of dose revealed the presence of heterogeneity 
of variance. Independent observations at each dose were used to estimate the variance of the response at each dose. Using the reciprocal of these variances made it possible to apply the more appropriate weighted regression analysis rather than unweighted regression analysis. A second-order polynomial function of dose was needed to describe the fecundity relations for each of the synthetic oils. However, the fecundity values from the petroleum did not change significantly $(P>0.10)$ over the experimental dose range. In addition, the behavior of the dose-fecundity functions was found to be different for the two oils. The results from the analysis of the experimental data will be helpful in estimating the response of other hemipterans to exposure to a synthetic oil from an accidental spill.

\section{ANALYSIS OF PHOSPHORUS DEFICIENCY PATTERNS}

Many factors are known to control phytoplankton growth in aquatic ecosystems, including temperature, light availability, grazing by zooplankton and fish, and availability of chemical elements required for cell growth. In freshwater, phosphorus is the nutrient most often limiting algal growth. One way of assessing phosphorus deficiency in a phytoplankton community is to determine the alkaline phosphatase activity (APA). Alkaline phophatase is an enzyme produced by phytoplankton when external phosphorus concentrations fall very low. Therefore, if two samples contain the same amount of algal biomass, then the phosphorus limitation of the sample containing higher APA levels can be said to be more severe.

A study was conducted to obtain alkaline phosphatase values from various areas and depths of three TVA reservoirs. The APA data are usually summarized in terms of a specific APA level, which is the alkaline phosphatase activity normalized to the size of the phytoplankton community producing it. This normalization is accomplished by dividing the phosphatase activity of a sample by the corresponding chlorophyll $A$ concentration. Independent estimates of the phosphatase activity and chlorophyll A concentrations were available and confidence limits on the specific APA were derived. 
An application of Fieller's theorem made it possible to derive an expression for the variance of the specific APA as a function of the variances associated with the phosphatase and chlorophyll A concentrations. In addition, Satterthwaite's approximation was used to approximate the degrees of freedom of the variance of the specific APA necessary to calculate appropriate confidence limits. The results of this analysis were helpful in evaluating the seasonal pattern of phosphorus deficiency over the growing season and in assessing the spatial distribution of phosphorus deficiency in the three reservoirs.

\section{EFFECTS OF A COAL LIQUID ON EMERGENCE OF POND INSECTS}

Emergence of aquatic insects has been used for a variety of research purposes and as an index of the effects of certain toxicants. In the present study the effect of a synthetic coal-derived liquid fuel on the emergence of pond insects was investigated. Twelve ponds, which were of similar construction and similar stock, were randomly allocated to one of six oil doses, two ponds per dose with one dose being a control. Floating emergence traps were placed in each pond, and the number of trapped insects in each trap were recorded weekly for a period of eight weeks. Pretreatment observations were also available on each pond to test for any initial pond differences. The observed number of trapped insects for each trap-date combination were classified according to taxon.

The main goal of the data analysis was to test for a significant dose effect on the emergence patterns. The usual univariate analysis of variance techniques with dose and time as factors were not appropriate. This was because of the lack of independence among the observations on a particular pond which was the basic experimental unit. To compensate for this difficulty, the multivariate technique of profile analysis ${ }^{5}$ with its associated multiple comparison procedures was used to test for significant pretreatment differences and for significant dose effects for each of the taxa. No significant pretreatment differences were found among the ponds. Significant 
$(P<0.05)$ dose effects were observed for total number of insects as well as for various constituent taxa.

\section{PREDATOR-PREY MODEL}

In many aquatic studies it is important to have a realistic model to describe the amount or weight of prey fish consumed by a predator fish. The understanding of this phenomerion can be quite usetul in developing a model for an aquatic ecosystem. In the proposed model to describe the distribution of the weight of prey fish consumed by a predator fish, the number of fish consumed was assumed to be a truncated Poisson random variable and the weight of each consumed fish was assumed to be a normal or lognormal random variable. The random variable associated with the weight of consumed fish is known as a compound Poisson random variable. With the previously stated assumptions, expressions for the mean and variance of the compound Poisson random variable were derived in closed forn for the two cases:

(1) when the weight of consumed fish was normally distributed, and (2) when the weight of consumed fish was lognormally distributed. It is expected that the adequacy of the assumptions will be tested and the derived expressions will be used with subsequent experimental data.

\section{COMBINING UNCERTAINTIES IN ENVIRONMENTAL RISK ASSESSMENT}

One of the goals of environmental risk assessment is to predict the probability of an effect of a contaminant on various endpoints such as fish mortality. The logistic dose-response curve has been used to describe fish mortality for a given combination of species and chemical. The method described by Brand et al. ${ }^{6}$ can be used to obtain confidence bands for the estimated mortality curve as well as its inverse. This makes it possible to calculate confidence limits on the estimated mortality for a given dose or, for the inverse problem, to calculate confidence limits on a dose for a given level of mortality. In field situations, the contaminant concentration in a body of water cannot be predicted without error. However, it is often possible to 
associate a confidence interval, say $100(1-\gamma) \%$, with the unknown mean contaminant concentration. A method has been developed to calculate confidence limits with a specified lower bound confidence, say $95 \%$, of including the true but unknown response at the true but unknown mean contaminant concentration. This interval reflects the error associated with the estimated contaminant concentration as well as the error associated with the estimated dose-response curve.

\section{REFERENCES}

'Environmental Sciences Division.

University of the South.

3University of Tennessee and Environmental Sciences Division.

${ }^{4}$ J. E. Grizzle and D. A. Allen, "Analysis of Growth and Dose-Response Curves," Biometrics, 25, 357-381 (1969).

${ }^{5}$ D. F. Morrison, Multivariate Statistical Methods (2nd ed.) McGraw-Hill, New York, 1976.

${ }^{6}$ R. J. Brand, D. E. Pinnock, and K. L. Jackson, "Large Sample Confidence Bands for the Logistic Response Curve and its Inverse," The American Statistician, 27, 157-160 (1973). 


\section{HEALTH AND SAFETY}
G. R. Handley ${ }^{l}$
M. D. Morris
C. M. Hopper
J. N. Underwood ${ }^{1}$
E. Leach
C. M. West ${ }^{1}$
W. E. Lever
E. A. Zeighami ${ }^{2}$

\section{CANCER INCIDENCE RATES IN RADIATION-EXPOSED POPULATIONS}

Some proposed compensation plans specify Lhal din individual who has developed cancer after being exposed to nuclear weapurs lesls would be compensated based on the increased inciderice risk for that individual. For any specific individual, age at observation (of cancer) is known and it is assumed that dose may be approximated. Incidence rates have been approximated specific to age at exposure and dose, but it is generally unknown what risk values are specific to age at observation and dose. Hence the cost of proposed compensation plans is not known.

We have written a computer program, LIFE2, which simulates the risk experience of a population due to a single-exposure event. Input includes proportions of the population which are exposed at each dose and age. Numbers of new cases and incidence rates speciflc to each aye at observation and dose are calculated using life table techniques. The program is intended for use as a tool in assessing the practicality of proposed compensation plans.

\section{CARDIOVASCULAR DISEASE AND MINERAL ELEMENTS IN DRINKING WATER}

An ongoing study or drinking water characteristics and mortality from coronary heart disease is based on data being collected un deceased dairy farmers in wisconsin. Sampling is accomplished through death certificate searches; and data are collected from death certificate information, physician questionnares, and laboratory analysis of well water at the residence of each participant. 
Much of our involvement during the data collection phase of the study has been in data validation. In addition some associations among variables from the water analyses have been investigated. Some preliminary analyses of associations between cause of death and water characteristics (particularly levels of heavy metals) have been carried out on the incomplete data.

Data collection was completed early in 1983, and compilation of the computer data set should be completed by June, 1983. Statistical analysis of associations between mortality characteristics and drinking water characteristics should be completed by early 1984 .

\section{ACCEPTANCE SAMPLING PLAN FOR RASCHIG RINGS}

An acceptance sampling plan was developed for lots of. Borosilicate-glass Raschig rings to meet the specifications laid out in Health and Safety Procedure 70-155. The plan addresses both chemical composition and shock resistance requirements. The chemical composition requirements were evaluated by fixed sample procedures, while the shock resistance requirements were treated by sequential procedures.

\section{CALIBRATION OF TLD BADGES}

The study of the thermoluminescent dosimeter (TLD) badges has continued. The effort has been centered on studies related to understanding the fading process. Results of long-term studies contributing to greater understanding of the process indicate that the TLD measurements fade about $15 \%$ over a one-year period.

\section{GRAPHICAL DISPLAY OF AIR MONITORING DATA}

Currently there are approximately 400 air filters located in about 70 areas in the $Y-12$ Plant that monitor radioactivity levels in the air. Prior to this year, these data have been displayed in current reports and then stored on computer tapes. 
At this time, computer software is being designed that will allow Health Physics personnel to graphically investigate current and prior trends in the data using the ORNL computer facilities either in an interactive or batch mode. In addition to individual sample plots, the system allows for daily, monthly, and quarterly plots averaged by areas.

\section{TOLERANCE LIMITS FOR SIMULATED K-EFFECTIVES}

Simulated K-effective values for cylindrical shapes containiny specified masses of enryched urantum and water were related to the inside diameter of the cylinder and to the mass of uranium by a functional relationship. This relation was used to produce tolerance bounds for the K-effectives. The simulated $K$-effectives were produced by the KENO-IV, CSRL code for 24 combinations of mass and cylinder di ameter.

\section{REFER[NC[S}

${ }^{1}$ Health, Safety and Environmental Affairs Division.

${ }^{2}$ Health and Safety Research Department. 


\title{
13. SAFEGUARDS
}

\author{
K. 0. Bowman \\ R. Counts ${ }^{1}$ \\ L. J. Gray \\ T. L. Hebble \\ S. J. Hurrell $1^{2}$ \\ H. T. Kerr ${ }^{2}$ \\ V. Lowe

\section{PROPOSED NRC REGULATIONS AND LOSS DETECTION CAPABILITIES IN REPROCESSING PLANTS}

A program has been initiated to support efforts by the Nuclear Regulatory Commission (NRC) to improve existing Material Control and Accounting (MC\&A) regulations. The September 10, 1981, version of the proposed Category I MC\&A Reform Amendment which appeared in Volume 46, No. 175 of the Federal Register was written primarily for existing nuclear material licenses; reprocessing plants were specifically exempted. After reviewing public comment, NRC extended the application of the proposed rules to include reprocessing plants.

The current program is to determine whether a large reprocessing plant can meet the requirements of the proposed Category I MC\&A Reform Amendment. The conclusions are intended to be applicable to any large Purex reprocessing design. For the purposes of this study, the reference reprocessing facility is the Barnwell Nuclear Fuel Plant (BNFP) located in Barnwell, South Carolina.

Fundamentally, the problem revolves around estimating loss detection capabilities of a reprocessing plant and determinimy if these capabilities meet the proposed standards set by NRC. As a first step the BNFP facility is being partitioned into four material accounting areas (MAA) with known transfers and inventories. From information supplied by BNFP personnel, material balances with corresponding estimates of variance will be determined. The results are expected to isolate areas which may not mect the proposed rules. A major problem will be the estimation of process variation and how it is to be incorporated into the comparison with NRC rules. 


\title{
CALCULATING CONTROL LIMITS FOR INVENTORY DIFFERENCES
}

The DOE has required the $Y-12$ Plant to submit a formal action plan for developing statistically sound control limits for inventory differences. A computer program has been written to simulate inventory transitions. Results from these simulations have been used to investigate the statistical behavior of potential inventory differences. Some points have emerged for further study.

\section{SHADING BY $\wedge$ RECTANGLE}

We consider the following situation: a rectangle of sides $a, b$ is "flattened" onto the surface of a hemisphere of radius $R$ which is sitting on top of the $x-y$ plane. The rectangle is aligned so that the axis of length $b$ lies on a side through the pole of the hemisphere. Assuming that light comes in parallel to the z-axis, what is the area of the rectangle's shadow on the $x-y$ plane?

Under a simple assumption which defines the "flattening" process, the area of the shadow is

$$
a R\left[\sin \left(\emptyset_{0}+b / R\right)-\sin \emptyset_{0}\right]
$$

where $\emptyset_{0}$ is the polar angle at the top of the rectangle.

\section{REFERENCES}

\author{
${ }^{1} Y-12$ Quality Uivision. \\ ${ }^{2}$ Engineering Technology.
}




\section{PART C. EDUCATIONAL ACTIVITIES}

Mathematics and Statistics Research (MSR) is active in a number of educational areas of both a professional and academic nature. This year MSR personnel were responsible for the organization of a workshop on the Propagation of Uncertainties, a small Conference on the Quality of Data collected by Data Collection Systems, and a symposium on sparse matrix computations. MSR personnel have continued to be involved with various forms of the in-hours training program. Personnel have also served as visiting lecturers to colleges and universities, through the Oak Ridge Associated Universities (ORAU) program, and the visiting lecture program of the Committee of Presidents of Statistical Societies (COPSS). In addition, MSR personnel have supervised students through the ORAU, the Southern Colleges and Universities Union (SCUU), and the Great Lakes Colleges Association/Associated Colleges of the Midwest (GLCA/ACM) programs. Finally, interaction with college and university personnel is encouraged through time release programs, short-and long-term visits, and the use of consultants.

\section{WORKSHOPS AND CONFERENCES}

A small conference on the Iniprovement of The Quality of Data Collected by Data Collection Systems was held in Oak Ridge during November 11-12, 1982. In excess of 20 invited and contributed papers were presented and discussed. The topics included: samples vs rensuses; error profiles; exploratory data analysis; pattern recuynition; outlier detection; sampling frames; questionnaire design; 
automatic data editing; and incomplete data. T. Wright served as the chairman of the organizing committee. Major funding for the conference came from the Office of Naval Research.

A workshop on the Propagation of Uncertainties was held during October 7-8, 1982, in 0ak Ridge. The workshop was organized into three technical sessions in which invited participants presented papers. A fourth session was devoted to the discussion of the papers. One of the main purposes of the workshop was to make an assessment of the stateof-the-art of the available methods, and to get an understanding of their strengths and weaknesses. The workshop was sponsored by the Nuclear Regulatory Commission, with V. R. R. Uppuluri acting as one of the co-chairmen.

Sparse Matrix Symposium 1982, the most recent in a series of major conferences dealing with general aspects of sparse matrix technology, was held at Fairfield Glade, Tennessee, during October 24-27, 1982. The symposium brought together 121 mathematical scientists and engineers from industry, government, and academic institutions who were concerned with problems involving the rigorous mathematical development of algorithms and software for large-scale computations. The formal program consisted of 8 invited talks, 48 contributed talks, and 7 contributed poster presentations. In addition, 3 informal sessions were organized and held during the symposium. A catalog containing 123 one-page descriptions of available sparse matrix software was distributed to the attendees. The symposium was sponsored by the Army Research Office, the Office of Navai Research, and MSR. K. C. Ward served as Symposium Chairman, R. E. Funderlic and M. I. Heath were members of the Organizing Committee, and $M$. T. Heath presented one of Llie invited taiks.

\section{IN-HOUSE EUUCATIONAL PROGRAMS}

J. J. Beauchamp, D. G. Gosslee, T. L. Hebble, T. J. Mitchell, M. D. Morris, R. L. Schmoyer, and C. K. Bayne of MSR and S. A. McGuire of the Y-12 Quality Division were course instructors for SAS Statistics, a course given during the winter term as part of the ORNL 
In-Hours Continuing Education Program. The course was intended to provide detailed statistical background to certain SAS procedures for individuals already familiar with SAS. An introductory level of statistical understanding was also assumed.

J. J. Beauchamp and M. D. Morris taught an Introduction to Practical Statistics course during the fall quarter as part of the ORNL In-Hours Continuing Education Program. This course is an introduction lo statistical methods and includes material on descriptive statistics, t-tests, linear regression, and one-way analysis of variance.

J. J. Beauchamp and R. L. Schmoyer presented an eight-week seminar series on regression diagnostics and robust regression for members of the ORNL Environmental Sciences Division. The topics presented included: review of nultiple linear regression and the output from the SAS GLM and REG procedures; presentation of measures for diagnosing influential data points; and introduction to robust regression.

M. T. Heath taught a course on Computer Methods for Mathematical Computations during the winter quarter as a part of the ORNL In-Hours continuing Education Program. The emphasis of this course was on the use of high-quality numerical sof tware to solve mathematical problems such as systems of linear or nonlinear algebraic equations, interpolation, integration, differential equations, optimization, least squares, and eigenvalue problems.

C. A. Serbin organized and taught the Introduction to FORTRAN IV and the Interilediate FORTRAN IV courses during the fall and spring quarters, respectively, as a part of the Y-12 In-Hours Computing Education Program. The intent of the courses was to explain the features of the FORTRAN IV programming language and to emphasize good programming practices.

V. R. R. Uppuluri and C. C. Travis of the ORNL Health and Safety Research Department taught a course on Probab1listic Methods in Risk Analysis during the winter quarter as part of the ORNL In-Hours Continuing Education Program. The course covered the basic tools in probability theory, in addition to Bayes' Theorem. The applications wcrc directed at nuclear safety and health risks problems.

T. Wright taught a course on Statistical Methods for Quality Improvement during the spring quarter. The course was sponsored by the 
ORNL Quality Assurance Coordinator. The topics covered were: elementary probability and statistics, sampling, cause and effect diagrams, histograms and Pareto Charts, control charts, and confidence interval estimation.

\section{SEMINAR SERIES}

The department conducts a biweekly seminar series dealing with the consulting and research activities of its staff. This series is augmented from time to time with outside speakers. The names of the speakers, their organfzaclonal afflliatlons, if not with MSR, dild lie titles of their talks are listed at the end of this section. The series is coordinated by D. G. Wilson.

\section{TRAVELING LECTURERS}

Various department members have participated in traveling lecture programs. K. O. Bowman participated in the COPSS lecture program, while V. R. R. Uppuluri, R. L. Schmoyer, and A. D. Solomon participated in the ORAU lecture program. Typically, lecturers visit the sponsoring universities and consult with their mathematicians and statisticians. A lecture for the undergraduate and graduate students is always given. Titles of these lectures are given at the end of this section.

\section{SUPEKVIISIONN OF STUDENTS}

Students regularly work with MSR staff members under the sponsorship of the GLCA/ACM and SCUU Science Semester programs and the ORAU Student Research Participation programs as URAU Graduate Fellows and as summer einployees. In addition, several students have participated in co-op programs for which time is spent at MSR.

P. K. Sluber, a cu-up student früm Tennessee Technological University spent June 1981 through August 1982 working with R. E. Funderlic on computational problems in rotor dynamics for the Separation systems Division. Another co-op student from Tennessee Technological 
University, M. L. Stephens, continued the work of Stuber from August 1982 through the report period and will continue on through August 1983. Their work is reported in Part B of this report.

T. L. Engel, a 1983 ORAU summer research participant from Virginia Polytechnical Institute and State University, worked with V. R. R. Uppuluri on problems associated with Risk Analysis.

M. D. Escobar, a summer research intern from the Departinent of Statistics at Vale University, spent the summer of 1933 working on problems in computational statistics. His work was directed by T. J. Mitchel1.

G. Hall, a SCUU student from Millsaps College, worked with A. D. Solomon from January through August 1983. He concentrated on the area of artificial intelligence in communication.

A. K. Sen, a summer research intern froin the Department of Physics at Ohio State University, spent the summer of 1983 working on computational problems related to the electronic density of states in liquid metal. His work was directed by L. J. Gray.

C. H. Shum, a GLCA/ACM student from Hope College, worked with A. D. Solomon from October through December 1982. His work concerned robotics and the use of artificial intelligence in strategy planning and obstacle avoidance.

W. M. Wood, a 1982 ORAU summer research participant from Reed College, worked with L. J. Gray and S.-J. Chang on boundary integral equation methods for nondestructive tesling problems.

\section{UNIVERSITY TEACHING ACTIVITIES}

L. J. Gray taught three courses, Linear Algebra, Advanced Linear Algebra, and Complex Analysis, for the University of Tennessee Department of Mathematics during the school year.

T. J. Mitchell taught a course, Statistics for Biologists, for the University of Tennessee Graduate School of Biomedical Sciences during the summer quarter.

M. D. Morris taught two courses, Probability and Statistics for Engineers, and Statistical Mcthods, for the Uiiriversily of Tennessee Department of Statistics during the school year. 
A. D. Solomon taught three courses, Data Base Management Systems, Data Structures, and Simulation and Systems Programming, for the University of Tennessee Department of Computer Science, and one course, Differential Equations, for the Department of Mathematics.

T. Wright taught two courses, Calculus of Several Variables and Linear Algebra, for the Knoxville College Department of Mathematics and Physics, and two courses, Survey Sampling and Introductory Statistics, for the University of Tennessee Department of Statistics.

\section{SHORT-TERM VISITING RESEARCHERS}

A number of researchers visited MSR for several days to consult with department members on mathematical and statistical problems. Professor G. J. Davis, Department of Mathematics, Georgia State University, visited on June 8-10, 1983, working with R. C. Ward on problems in numerical linear algebra.

Dr. U. Gotz, Sandoz Ltd., Basel, Switzerland, visited on November $8-12,1982$, to discuss the design and analysis of survival; sacrifice animal experiments with T. J. Mitchell.

Protessor A. 1. Laub, Department of Electrical Engineering, Iniversity of Southern California, visited on June 14-17, 1983, working with M. T. Heath and R. C. Ward on linear algebra probleins arising in control theory.

Professor C. C. Paige, Department of Computer Science, MCGill University, visited on June 13-17, 1983, working wilh M. I. Heath and R. C. Ward on linear algebra problems arising lil cunlrul theory. Professor D. S. Robson, Biometrics Unit, Cornell University, v1sited on June 6-10, 1903, to curliult with J. J. Pr.auchamp. T. J. Mitchell, and M. D. Morris on research problems in the Analysis of Large Data Sets project.

\section{LONG-TERM VISITING RESEARCHERS}

Professor J. J. Buckley, Department of Mathematics, University of Alabama at Birmingham, visited with V. R. R. Uppuluri during June 1983 
on a Faculty Participation Agreement with ORAU. They conducted research in the areas of combining expert opinion and in ranking methods.

Professor M. V. Foster, Department of Mathematics, Southwest Missouri State University, spent ten weeks from June through August 1983 as a Faculty Research Participant of ORAU. He worked with T. J. Mitchell on problems associated with computational statistics.

Professor J. A. George, Dean of the Faculty of Mathematics, University of Waterloo, visited on April 11-22, 1983, working with M. T. Heath on large, sparse systems of linear equations and least squares problems.

Professor J. R. Gilbert, Department of Computer Science, Cornell University, visited on June 20-July 15, 1983, working with M. T. Heath on problems in sparse matrix computations.

Professor S. W. Looney, Louisiana State University, spent ten weeks from June through August 1982 as a Faculty Research Participant of ORAU. He worked with V. R. R. Uppuluri on the problem of the propagation of uncertainties.

Professor S. A. Patil, Mathematics Department, Tennessee Technological University, visited V. R. R. Uppuluri periodically from October 1982 through June 1983 on a Faculty Participation Agreement with ORAU. Research was conducted on empirical Bayesian methods and waiting time problems with applications to problems in nuclear safety.

Professor D. S. Scott, Department of Computer Science, University of Texas at Austin, visited on January 3-7 and March 14-18, 1983, working with R. E. Funderlic, M. T. Heath, and R. C. Ward on problems in numerical linear algebra.

Professor L. R. Shenton, Computing and Information Services, University of Georgia, visited for two weeks, from August 20 to September 2, 1982. He consulted with $k$. 0. Buwnan on research problems in statistical methods relating to computational statistics.

Professor B. W. Turnbull, Department of Operations Research and Industrial Engineering, Cornell University, visited during 0ctober 4-7, 1982, and March 24-26, 1983. He worked with T. J. Mitchell on methods for the design and analysis of survival/sacrifice animal experiments. 


\section{LIST OF CONSULTANTS}

J. A. George, University of Waterloo

G. H. Golub, Stanford University

G. P. McCabe, Purdue University

R. J. Plemmons, North Carolina State University

J. B. Robertson, University of California at Santa Barbara

D. S. Robson, Cornell University

L. R. Shenton, University of Georgia

n. S. Scott, University of Texas at Austin

R. W. Turnbull, Cornell University

\section{MSR SEMINARS}

J. J. Beauchamp, "Assessment of Fisher and Logistic Linear and Quadratic Discrimination Models," July 7, 1982.

E. L. Frome, "Poisson Regression Analysis of Cytogenetic Dose-Response Curves," July 21, 1982.

S. W. Louney, Louisiana State University, "Graphical Techniques for Assessing Goodness of Fit," August 4, 1982.

W. M. Wood, "Numerical Analysis of a Two-Dimensional Elastodynamic Systeil," August 11, 1982.

S.-J. Chang, "Inclined Pile-Up at Dislocations at the Crack Tip," August 18, 1982.

V. R. R. Uppuluri, "Prediction and Estimation Based on Empirical Bayesian Methods," September 1, 1982.

R. L. Schmoyer, "Sigmoidally Constrained Maximum Likelihood Estimation in Quantal Bioassay," September 15, 1982.

1. Fircar. "Rounding Errors of the Lanczos Algorithm," September 23, 1982.

D. G. Wilson, "A Shortcoming of the Explicit Solution for a Binary All oy Solidification Problem," September 29, 1982.

B. W. Turnbull, Cornell University, "Sequential Design for Uestructive Life-Testing, With Application to Animal Sacrifice Experiments," October 6, 1982. 
M. T. Heath, "Numerical Methods for Large Sparse Linear Least Squares Problems," October 20, 1982.

A. D. Solomon, "Some Remarks on Artificial Intelligence and Communications, Engineering and Computer Science," November 3, 1982.

T. Wright, "On a Comparison of the Quantity of Information Given by Two Beta Priors When Estimating the Difference Between Two Proportions," November 17, 1982.

T. J. Mitche11, "A Computer Prograll for the Statistical Analysis of Disease Prevalence Data From Survival/Sacrifice Experiments," December 1., 1982.

R. E. Funderlic, "A Combined Direct-Iterative Method for Certain M-Matrix Linear Systems," December 15, 1982.

A. D. Solomon, "A Film and Discussion on Robotics Featuring 'Shakey' the Robot," January 3, 1983.

V. Alexiades, "Modeling of the Binary Alloy Solidification Process," January 14, 1983.

L. J. Gray, "Introduction to Renormalization Group Theory," January 26 , 1983.

T. L. Hebble, "Hypothes is Testing in Safeguards," February 23, 1983.

K. 0. Bowman, "Maximum Likelihood Estimators for the Gamma Distribution - Revisited," March 9, 1983.

G. A. Geist, "Minimization of Mechanical Complexity in Robotics," March 10, 1983.

R. C. Ward, "A Jacobj-Like Eigenvalue Algorithm for Sparse, Symmetric Matrices," March 23, 1983.

G. P. Patil, Pennsylvania State University, "Multimodel Modeling and Data Analysis with Applications to Recruitment," March 24, 1983.

J. J. Beauchamp, "A Progress Report on the Program Directions for Research in Statistical Methods Document," April 6, 1983.

D. G. Gosslee, "Correlation and Regression Diagnostics: Investigating the Relationship of the Toxic Effects and the Properties of Metal Ions," April 20, 1983.

A. D. Solomon, "Strategy Planning for a Small. Robotic Arm," May 4, 1983. 
S. F. Ebey, "The Solution of an Experimental Design Problem Involving a First Order Autoregressive Model," May 18, 1983.

S. C. Peters, Stanford University, "Bootstrapping a Regression Equation: Some Empirical Results," May 23, 1983.

W. E. Lever, "An Update on the TLD Meter Badge Problem," June 1, 1983.

V. R. R. Uppuluri, "Man and Machine: Probabilistic Learning Models," June 15, 1983.

G. Ostrouchov, "Sparse Linear Least Squares Computations Using a Bipartite Graph Model of Givens Transformations," June 16, 1983.

T. J. Mttche11, "Cuinputer Algorithms For Dcsigning Experimants Under Two Criteria," June 29, 1983.

\section{ORAU TRAVELING LECTURE PRESENTATIONS}

R. L. Schmoyer, "Sigmoidally Constrained Maximum Likelihood Estimation in Quantal Bioassay," Medical University of South Carolina, Charleston, South Carolina, January 27, 1983.

A. D. Solomon, "Artificial Intelligence--What it is Now and What it May Become in the Future," presented at the Oklahoma City University, January 14, 1983.

V. R. R. Uppuluri, "Prediction and Estimation Based on Empirical Bayesian Methods," presented as a colloquium at the Departinent of Statistics, University of Kentucky, Lexington, Kentucky, April 28 , 1982.

\section{COPSS TRAVELING LECTURE PRESENTATIONS}

K. 0. Bowman, "Maximum Likelihood Estimators for the Gamma Distribution," Department of Mathematics, University of Alabama in Huntsville, April 22, 1983.

K. 0. Bowman, "Topics in the History and Application of Statistics," Department of Mathematics, University of Alabama in Huntsville, April 22, 1983.

K. 0. Bowman, "The Estimation Problems With Some Historical Notes," Mathematics Department, Roane State Community College, Harriman, Tennessee, May 4, 1983. 
PART D. PRESENTATIONS OF RESEARCH RESULTS

\section{PUBL ICATIONS}

\section{BOOKS AND PROCEEDINGS}

V. Alexiades and C. Y. Chan, ${ }^{1}$ "A Singular Fourier Problem With Nonlinear Boundary Conditions," in Proceedings of the International Conference at the University of Texas at Arlington, June 1980, Academic Press, New York, 1982.

C. K. Bayne, ${ }^{2}$ J. J. Beauchamp, and V. E. Kane, ${ }^{3}$ "A Review and Recent Results of the Performance of Classification Functions Under Nonoptimal Conditions," pp. 29-37 in Proceedings of the 1982 DOE Statistical Symposium, October 13-15, 1982, EG\&G Idaho, Inc., Idaho Falls, Idaho.

K. 0. Bowman and L. R. Shenton, 4 "Moment Series for Moment Estimators of the Parameters of a Weibull Density," pp. 174-186 in Proceedings of Computer Science and Statistics: 14th Symposium on the Interface, Springer-Verlag, New York, 1983.

K. 0. Bowman and L. R. Shenton, "Johnson's Translation System," Encyclopedia of Statistical Sciences, vol. 4, ed. by S. Kotz and N. L. Johnson, John Wiley and Sons, Inc., New York (forthcoming 1983).

K. 0. Bowman and L. R. Shenton, 4 "Levin's Summation Algorithm," Encyclopedia of Statistical Sciences, vol. 4, ed. by S. Kotz and N. L. Johnson, John Wiley and Sons, Inc., New York (forthcoming 1983). 
K. 0. Bowman and L. R. Shenton, " "Method of Moments," Encyclopedia of Statistical Sciences, vol. 5, ed. by S. Kotz and N. L. Johnson, John Wiley and Sons, Inc., New York (forthcoming 1984).

K. 0. Bowman and L. R. Shenton, " "The Padẹ and Stieltjes Transformation," Encyclopedia of Statistical Sciences, vol. 6, ed. by S. Kotz and N. L. Johnson, John Wiley and Sons, New York (forthcoming 1984).

K. 0. Bowman and L. R. Shenton, ${ }^{4}$ Moment $\left(\mathrm{d}_{1}, \mathrm{~b}_{2}\right)$ Techniques, Handbook of Goodness of Fit Techniques, ed. by R. B. D'Agostino and M. Stephens, Marcel Dekker, Inc., New York (forthcoming).

K. 0. Büwan and L. R. Shenton, "Properties of Estiuliturs for the Gamma Distribution, Marcel Dekker, Inc., New York (forthcoming).

D. J. Downing ${ }^{2}$ and V. R. R. Uppuluri, "Propagation of Uncertainties: An Overview," pp. 171-192 in Proceedings of the 1982 DOE Statistical Symposium, October 13-15, 1982, EG\&G Idaho, Inc., Idaho Falls, Idaho.

M. A. Kastenbaum ${ }^{5}$ and K. 0. Bowman, "Optimal Sample Size Requirements," Encyclopedia of Statistical Sciences, vol. 6, ed. by S. Kotz and N. L. Johnson, John Wiley and Sons, Inc., New York (forthcoming 1984 ).

C. C. Lushbaugh, ${ }^{6}$ S. A. Fry, ${ }^{6}$ C. M. Shy, ${ }^{7}$ and E. L. Frome, "DOE Health and Mortality Studies at 0ak Ridge," in Proceedings of the S1xteenth Midyear Topical Symposium, Health Physics Society: Epidemiology Applied to Health Physics, January 9-13, 1983, Albuquerque, New Mexico (forthcoming).

S. M. Ohr, ${ }^{8}$ J. A. Horton, ${ }^{9}$ and S.-J. Chang, 10 "Direct Observations of Crack Tip Dislocation Behavior Uuring Tenstle dnd Cyclic Deformation," in Proceedings of the Ser.nnd International Symposium on Defects, rracturc, dnd Fatigue, Mont Gabriel, Canada, May 30-June 5, 1982 (forthcoming).

A. D. Solomon, "Some Aspects of the Computer Simulation of Conduction Hcat Transfer and Phase Change Processes," pp, 457-470 in Computing Methods in Applied Sciences and Engineering, ed. by V. R. Glowinski and J. Lions, North Holland Publishing Company, Groningen, The Netherlands, 1982. 
D. G. Wilson, A. D. Solomon and V. Alexiades, "Proyress With Simple Binary Alloy Solidification Problems," in Proceedings of the Symposium on Free Boundary Problems, Montecatini, Italy, June 18-26, 1981, ed. by Antonio Fasano and Mario Primicerio, Pitman Publishers, London, England, 1983.

\section{JOURNAL ARTICLES}

V. Alexiades, "Generalized Axially Symmetric Heat Potentials and Singular Parabolic Initial-Boundary Value Problems," Archive for Rational Mechanics and Analysis, 79(4), 325-350 (1982).

V. Alexiades, "Rapid Freezing of Dilute Alloys," IMA J. Applied Math. (forthcoming).

V. Alexiades and E. C. Aifantis, 11 "Singular Problems in the Theory of Stress-Assisted Diffusion," SIAM J. Math. Anal. (forthcoming).

K. Anderson, 12 M. Sobel, 13 and V. R. R. Uppuluri, "Quota Fulfillment Times," The Canadian Journal of Statistics, 10, 73-88 (1982).

C. K. Bayne, ${ }^{2}$ J. J. Beauchamp, V. E. Kane, ${ }^{3}$ and G. P. MCCabe, 14 "Assessment of Fisher and Logistic Linear and Quadratic Discrimination Models," J. Am. Stat. Assoc. (subinitted).

C. K. Bayne, ${ }^{2}$ J. J. Beauchamp, and V. E. Kane, 3 "Misclassification Probabilities for Second-Order Discriminant Functions Used to Classify Bivariate Normal Populations," Commun. Stat. B - Simul. Comput. (submitted).

J. J. Beauchamp and V. E. Kane, ${ }^{3}$ "Application of the Power-Shift Transformation," J. Stat. Comput. Simul. (submitted).

J. J. Beauchamp and V. E. Kane, ${ }^{3}$ "Robustness of Three Power Transformation Estimation Procedures," J. Stat. Comput. Simul., 15, 251-272 (1982).

K. 0. Bowman, "Computation of the Polygamma Functions," Commun. Stat. B Simul. Comput. (submitted).

K. 0. Bowman, "Extended Moment Series and the Parameters of the Negative Binomial Distributions, Biometrics (forthcoming).

K. 0. Bowman and L. R. Shenton," "Continued Fractions and the Polygamma Function's," J. Computa. Appl. Math., 9, 29-39 (1983). 
K. 0. Bowman and L. R. Shenton, 4 "Maximum Likelihood Estimators for the Gamma Distribution Revisited," Commun. Stat. B - Simul. Comput. (forthcoming).

S.-J. Chang ${ }^{10}$ and S. M. Ohr, ${ }^{8}$ "Effect of Thickness on Plastic Zone Size in BCS Theory of Fracture," Int. J. Fracture, 21, 3 (1983).

D. K. Cox ${ }^{15}$ and J. J. Beauchamp, "Thermal Resistance of Juvenile Crayfish, Cambarus bartoni (Fabricius): Experiment and Model," The American Midland Naturalist, 108, 187-193 (1982).

E. L. Frnme, "Fisher's Exact Variance Test for the Poisson Distribution," Appl. Statist., 31, 6\%-71.

E. L. Frome, "The Analysis of Rates Using Poisson Regression Models," Biometrics (forthcoming).

R. E. Funderlic, M. Neumann, ${ }^{16}$ and R. J. Plemmons, ${ }^{17}$ "LU Decompositions of Generalized Diagonally Dominant Matrices," Numerische Matnematik, 40, 57-69 (1982).

R. E. Funderlic and R. J. Plemrnons, ${ }^{17}$ "A Combined Direct-Iterative Method for Certain M-Matrix Linear Systems," SIAM J. Algebraic Discrete Meth. (rurthcoming).

J. A. George, ${ }^{18}$ M. T. Heath, and E. Ng, 18 "A Comparison of Some Methods for Solving Sparse Linear Least Squares Problems," SIAM J. SCt. stat. Comput. 4, 177187 (1983).

D. G. Gosslee, "Quantitative Aspects of Metal Ion Content and Toxicity in Drosophila," Toxicology (forthcoming).

M. T. Heath, "Some Extensions of an Algorithm for Spdr'se Lillear Least Squares Problems," SIAM J. Sci. Stat. Comput., 3, 223-237 (1982).

M. T. Heath, "Numerical Methods for Large Sparse Linear Least Squares Problems," SIAM J. Sci. Stat. Comput. (f urthicuming).

M. T. Heath, R. J. Plemmons, ${ }^{1 "}$ and R. C. Ward, "Sparse Orthogunal schemes for Structural Optimization Using the Force Method," SIAM J. Sci. Stat. Comput. (submitted).

P. J. Hakkinen, ${ }^{19}$ R. L. Schmoyer, and H. P. Witschi, 19 "Potentiation of Butylated Hydroxytolvene-Induced Acute Lung Damage by 0xygen," Amer. Rev. Respiratory Disease (forthcoming). 
R. P. Hemenger, ${ }^{20}$ T. Kaplan, ${ }^{8}$ and L. J. Gray, "Structure of Amphotericin B Aggregates Based On Calculations of Optical Spectra," Biopolymers, 22, 911 (1983).

J. M. Holland"1 and E. L. Frome, "Statistical Evaluations in the Carcinogenesis of Bioassay of Petroleum Hydrocarbons," Progress in Modern Environmental Toxicology (forthcoming).

J. M. Holland ${ }^{21}$ and T. J. Mitchell, "Effects of X-Irradiation on Survival and Disease Risk in Germfree Athymic Nude and Normal C3H Mice," Radiation Research (submitted).

V. E. Kane, ${ }^{3}$ R. C. Ward, and G. J. Davis, ${ }^{22}$ "Assessment of Linear Dependencies in Multivariate Data," J. Am. Stat. Assoc. (submitted).

T. Kaplan ${ }^{8}$ and L. J. Gray, "A Self-Consistent Approximation for MuffinTin Models of Random Alloys With Environmental Disorder," Phys. Rev. B (submitted).

S. J. Kennel, ${ }^{19}$ L. J. Foote, ${ }^{19}$ P. K. Lankford, ${ }^{19}$ M. Johnson, ${ }^{19}$ T. J. Mitchell, and F. R. Braslawsky, 19 "Direct Binding of Radioiodinated Monoclonal Antibody to Tumor Cells: Significance of Antibody Purity and Affinity for Drug Targeting or Tumor Imaging," Hybridoma (forthcoming).

R. Mills, ${ }^{23}$ L. J. Gray, and T. Kaplan, ${ }^{8}$ "Analytic Approximation for Random Muffin-Tin Alloys," Phys. Rev. B, 27, 3252 (1983).

T. J. Mitchel1, "Discussion (of 'Developments in Linear Regression Methodol ogy: 1959-1982' by R. R. Hocking)," Technometrics (forthcoining).

T. J. Mitchell and N. R. Draper, ${ }^{24}$ "Mixed Estimation Using 'Stable Response' Preference in Linear Regression, With Reference to Ridge Regression," Biometrika (submitted).

T. J. Mitchell and B. W. Turnbu11, ${ }^{25}$ "A Computer Program for the Statistical Analysis of Disease Prevalence Data From Survival/Sacrifice Experiments," Computer Programs in Biomedicine (submitted).

M. D. Morris, "Minimum Number of Runs for Two-Level Factorial Search Designs," J. Statis. Planning and Inference (submitted).

M. D. Morris and S. F. Ebey, ${ }^{26}$ "An Interesting Property of the Sample Mean IInder a First Order Autoregressive Model," Amer. Statist. (forthcoming). 
M. D. Morris and T. J. Mitchell, "Two-Level Multifactor Designs for Detecting the Presence of Interactions," Technometrics (forthcoming).

J. P. O'Neil127 and K. O. Bowman, "Effect of Selection Cell Density on the Recovery of Mutagen-Induced y-Thioguanine-Resistance Cells," Environ. Mutagenesis, 4, 627-637 (1982).

S. M. Ohr" and S.-J. Chang, 10 "Dislocation-Free Zone Model of Fracture: Comparison With Experiments," J. Appl. Phys., 53, 5645 (1982).

R. L. Schmoyer, "Everyday Application of the Cell Means Model," Amer. statist. (forthcoming).

R. L. Schmoyer, "Sigmoidally Constrained Maximum Likelihood Estimation in Quantal Bioassay," J.e Am. Stat. Assoc. (submitted).

R. L. Schmoyer and N. J. Price, "A Graphical Interpretation of Stein's Phenomenon," Amer. Statist. (submitted).

T. W. Schultz, ${ }^{19}$ J. N. Dumont, ${ }^{19}$ F. D. Sankey, ${ }^{19}$ and R. L. Schmoyer, "Structure Activity Relationships of Selected Napthalene Derivatives," Ecotoxicology and Environmental Safety (forthcoming).

L. R. Shenton" and K. 0. Bowman, "A Lagrange Expansion for the Parameters of Johnson's $S_{U}$," J. Stat. Comput. Simul., 15, 89-95 (1982).

A. D. Solomon, V. Alexiades and D. G. Wilson, "The Stefan Probleirl With a Convective Boundary Condition," Quar. Appl. Math., 40(2), 203-217 (1982).

A. D. Solomon, D. G. Wilson and V. Alexiades, "A Mushy Zone Model With an Exact Solution," Lett. Heat Mass Transfer, 9, 319-324 (1982).

A. D. Solomon, V. Alexiades and D. G. Wilson, "Explicit Solutions to Phase Change Problems," Quar. Appl. Math. (forthcoming).

J. B. Storer" 19 and T. J. Mitchell, "Limiting Values for the RBE of F1ssion Neutrurls at Low Doses for Life Shontsning in Mice." Radiase tion Research (submitted).

B. W. Turnbul1 $1^{25}$ and T. J. Mitchell, "Nonparametric Estimation of the Distribution of Time to Onset for Specific Diseases in Survival/ Sacrifice Experiments," Biometrics (forthcoming).

V. R. R. Uppuluri and W. Kuo, 28 "Survey of Error Propagation in Systems.," Microelectronics and Reliability (forthcoming). 
V. R. R. Uppuluri and R. Piziak, 29 "General Probabilistic Learning Models," Policy and Information (forthcoming).

R. C. Ward, G. J. Davis, ${ }^{22}$ and V. E. Kane, ${ }^{3}$ "An Algorithm for Linear Dependency Analysis of Multivariate Data," ACM Trans. Math. Software (submitted).

R. K. Williams, ${ }^{9}$ R. S. Graves, ${ }^{9}$ T. L. Hebble, D. L. McElroy, ${ }^{9}$ and J. P. Moore, ${ }^{30}$ "The Phonon and Electron Components of Thermal Conductivity of Tantalum at Intermediate Temperatures," Phys. Rev. B, 26(6) (1982).

D. G. Wilson, "Lagrangtan Coordinates for Moving Boundary Problems," SIAM J. Appl. Math., 42(6), 1195-1201 (1982).

D. G. Wilson, "Time Dependent Linear Transport II, Properties of Weak Solutions," J. Transport Theory and Stat. Phys. (forthcoming).

D. G. Wilson, A. D. Solomon, and V. Alexiades, "A Shortcoming of the Explicit Solution of the Binary Alloy Solidification Problem," Lett. Heat Mass Transfer, 9, 421-428 (1982).

L. L. Wright, ${ }^{15}$ J. S. Mattice, ${ }^{31}$ and J. J. Beauchamp, "Effects of Temperature and Sex on Growth Patterns in Nymphs of the Mayfly Hexagenia bilineata in the Laboratory," Freshwater Biology, 12, 535-545 (1982).

T. Wright, "An Inverse Sampled Bernoulli (ISB) Procedure for Estinating a Population Proportion With Nuclear Material Applications," Amer. J. Math. and Management Sci., 2, 123-134 (1982).

T. Wright, "Un Bayes Allocation of the Sample for Estimation of the Mean When Each Stratum has a Poisson Distribution," Commun. Statist. A Theory and Methods, 12, 409-426 (1983).

T. Wright and M. R. Chernick, 32 "Estimation of a Population Mean With Two-Way Stratification Using a Systematic Allocation Scheme," J. Statist. Planning and Inference, 7, 219-231 (1983).

E. A. Zieghami ${ }^{33}$ and M. D. Morris, "Estimation and Interpretation of the Proportional Mortality Ratio," Amer. J, Epidemiology, 117, 90-97 (1983). 


\section{REPORTS}

V. Alexiades, A. D. Solomon, and D. G. Wilson, Modeling Binary Alloy Solidification Processes, ORNL/CSD-117 (f orthcoming).

C. K. Bayne, ${ }^{2}$ J. J. Beauchamp, V. E. Kane, ${ }^{3}$ and G. P. McCabe, ${ }^{14}$ Assessment of Fisher and Logistic Linear and Quadratic Discrimination Models, ORNL/CSD/TM-200 (February 1983).

J. J. Beauchamp, T. Wright, F. J. Schultz, ${ }^{34}$ K. Haff, ${ }^{34}$ and R.J. Monroe, ${ }^{17}$ The Statistical Sampling Plan for the TRU Waste Assay Fdcilil.y, ORNL/CSD/TM-203 (rütlicuming).

K. 0. Bowman and E. Leach, Confidence Limits for the Expectation of a Poisson Variable, ORNL/CSD-115 (forthcoming).

K. 0. Bowman and L. R. Shenton, ${ }^{4}$ The Distribution of the Standard Deviation and Skewness in Gamma Sampling - A New Look at a Craig-Pearson Study, ORNL/CSD-109 (1983).

J. A. Carpenter, KWIC Index for Numerical Linear Algebra, ORNL/CSO-96 (March 1982).

J. A. Carpenter, KWIC Index for Numerical Linear Algebra, ORNL/CSU-106 (July 1982).

R. M. Counce, ${ }^{35}$ W. S. Groenier, ${ }^{36}$ I. L. Hebble, W. IJ. Holland, ${ }^{37}$ E. D. North, ${ }^{36}$ and I. F. Thompson, ir.. ${ }^{36}$ The Extractive Distillation of Nitric Acid Using the Two-Pot Concept, ORNL/TM-7982 (Decenber 1982).

E. L. Frome, J. M. Holland, ${ }^{21}$ and T. J. Mitchell, Statistical Methods Used to Quantify Skin Carcinogenicity, ORNL/CSD-113 (forthcoming).

R. E. Funderlic and R. J. Plemmons, ${ }^{1 "}$ A Combined Direct-Iterative Method for Certain M-Matrix Linear Systems, ORNL/CSD-11? (February 1983).

M. T. Heath, Numerical Methods for Large Sparse Linear Least Squares Problems, ORNL/CSD-114 (April 1983).

M. T. Heath, R. J. Plemmons, 17 and R. C. Ward, Sparse Orthogonal Schemes for Structural Optimization Using the Force Method, ORNL/CSD-119 (May 1983). 
T. L. Hebble, D. A. Canonico, ${ }^{38}$ D. R. Edmonds, ${ }^{9}$ and R. K. Nanstad, 9 An Analysis of Delta Ferrite Data From Stainless Steel Pipe Welds, ORNL/CSD/TM (forthcoming).

M. D. Morris, Screening Designs for Response Surface Experiments, ORNL/CSD/TM-159 (August 1982).

B. W. Turnbul1 ${ }^{25}$ and T. J. Mitchell, Nonparametric Estimation of the Distribution of Time to Onset for Specific Diseases in Survival/ Sacrifice Experiments, ORNL/CSD-111 (forthcoming).

V. R. R. Uppuluri, Expert Opinion and Ranking Methods, NUREG/CR-3115, ORNL/CSO/TM-201 (March 1983).

V. R. R. Uppuluri and $W$. Kuo, ${ }^{28}$ Survey of Error Propagation in Systems, NUREG/CR-2839, ORNL/CSD/TM-190 (April 1983).

D. G. Wilson, A. D. Solomon and V. Alexiades, A Model of Binary Alloy Solidification, ORNL/CSD-97 (August 1982).

\section{ORAL PRESENTATIONS}

V. Alexiades, "On Theories of Phase Transformations," presented at the Southeastern Regional Conference on Differential Equations, North Carolina State University, Raleigh, October 8, 1982.

C. K. Bayne, ${ }^{2}$ J. J. Beauchamp, and V. E. Kane, ${ }^{3}$ "A Review and Recent Results of the Performance of Classification Functions Under Nonoptimal Conditions," presented at the 1982 DOE Statistical symposium, Idaho Falls, Idaho, Octuber 13-15, 1982.

K. 0. Bowman, "Craig-Pearson Study of the Distribution of the Standard Deviation and Skewness in Gamma Sampling," presented at the E. S. Pearson Memorial Session, American Statistical Association Annual Meeting, Cincinnati, Ohio, August 16-19, 1982.

K. 0. Bowman and L. R. Shenton, ${ }^{4}$ "The Dark Side of Asymptotics and the Statistician," presented at the ENAR Biometric Society Spring Meeting, Nashville, Tennessee, March 1983.

S.-J. Chang ${ }^{10}$ and S. M. Ohr, ${ }^{8}$ "Inclined Pileup of Screw Dislocations at the Crack Tip," presented at the 112th Annual Meeting of AIME in Atlanta, Georgia, March 6-10, 1983. 
D. J. Downing ${ }^{2}$ and V. R. R. Uppuluri, "Estimation and Statistical Properties of the Output Function," presented at the Workshop on Propagation of Uncertainties, Oak Ridge, Tennessee, October 7-8, 1982.

D. J. Downing ${ }^{2}$ and V. R. R. Uppuluri, "Propagation of Uncertainties: An Overview," presented at the 1982 DOE Statistical Symposium, Idaho Falls, Idaho, October 13-15, 1982.

R. E. Funderlic, "Aspects of Being a Mathematician in Industry," Careers Seminạr presented at North Carolina State University, Raleigh, Fehruary 10, 1983.

R. E. Funderlic, "Solving Homogeneous Systems of Equations With Certain M-Matrices," presented at the National Bureau of Standards, Washington, D.C., November 11, 1982.

R. E. Funderlic and R. J. Plemmons, 17 "A Combined Direct-Iterative Method for Large-Scale Queueing Networks," presented at the SIAM 30th Anniversary Meeting, Stanford, California, July 19, 1982.

R. E. Funderlic and R. J. Plemmons, 17 "An Incomplete Factorization Method for Singular Irreducible M-Matrices," presented at the 1982 Sparse Matrix Symposium, Fairfield Glade, Tennessee, October 24, 1982.

D. G. Gosslee, "Sample Size and Power Calculations for Tests on Potential Mutagens," presented at the American Statistical Association Annual Meeting, Cincinnati, Onio, August 16-19, 1982.

D. G. Gosslee and S. F. Ebey, 26 "Levels of Significance of Tests on Small Proportions," presented at the ENAR Biometric society spring Meeting, Nashville, Tennessee, March 22, 1983.

M. 1. Heath, "Numerical Methods for Large Sparse Linear Least Squares Problems," presented at the Sparse Matrix Symposium, Fairfield Glade, Tennessec, October 26, 1983.

M. D. Morris and S. F. Ebey, 26 "An Interesting Property of the Sample Mean Under a First Order Autoregressive Model," presented at the ENAR Biometric Society Spring Meeting, Nashville, Tennessee, March 23, 1983. 
S. M. Ohr ${ }^{8}$ and S.-J. Chang, 10 "A Micromechanical Fracture Criterion," presented at the 112 th Annual Meeting of AIME in Atlanta, Georgia, March 6-10, 1983.

S. M. $0 h r^{8}$ and S.-J. Chang, 10 "Dislocation Generation at a Crack Tip," presented at the American Physical Society Meeting, Los Angeles, California, March 21-25, 1983.

C. A. Serbin, "A Finite Difference Code for Simulating Heating and Cooling Loads in a PCM-Enhanced Structure," presented at the SIAM 30th Anniversary Meeting at Stanford University, Palo Alto, California, July 20, 1982.

A. D. Solomon, "Perspectives on Artificial Intelligence and Robotics," presented at the Department of Mathematics, College of Charleston, Charleston, South Carolina, March 24, 1983.

H. Tsao ${ }^{39}$ and T. Wright, "A Frame on Frames: An Annotated Bibliography," presented at the Small Conference on the Improvement of the Quality of Data Collected by Data Collection Systems, Oak Ridge, Tennessee, November 11-12, 1982.

V. R. R. Uppuluri, "On Reciprocal Matrices and Their Applications," presented at Roane State Community College, Harriman, Tennessee (MAA Lecture), November 15, 1982.

V. R. R. Uppuluri, "Some Statistical Problems at a Modern Research Laboratory," presented at Centre College of Kentucky, Danville, Kentucky, April 29, 1983.

V. R. R. Uppuluri, "Some Mathematical and Statistical Problems in Risk Analysis," presented at the Colloquium in the Statistics Department, Pennsylvania State University, University Park, Pennsylvania, May 9 , 1983.

R. C. Ward, "Research in Numerical Linear Algebra: Current Status and Future Directions," presented as a seminar to the Departments of Matheiliditics and Physics and Astronomy, Georgia State University, Atlanta, Georgia, April 25, 1983.

R. C. Ward and.I. S. Duff, 40 "A Jacobi-like Eigenvalue Algorithm for Sparse Symmetric Matrices," presented as an invited lecture at the Seventh Annual Meeting of the Southeast Atlantic Section of SIAM, Clems on University, Clemson, South Carolina, March 26, 1983. 
R. C. Ward, V. E. Kane, ${ }^{3}$ and G. J. Davis, 22 "An Algorithm for Assessing Linear Dependencies in Multivariate Data," presented as a seminar to the Computer Science Department, Stanford University, Stanford, California, July 12, 1982.

D. G. Wilson, "A Model of Binary Alloy Solidification," presented at the SIAM 30th Anniversary Meeting at Stanford University, Palo Alto, California, July 20, 1982.

D. G. Wilson, "A Shortcoming of the Explicit Solution for the Binary Allny Solidification Problem," presented at the Southeastern Rcgional Conterence on Diffarentlal Equations, Ruleigh, North Carolina, October 8, 1982.

D. G. Wilson, "A Survey of Moving Boundary Problems," presented at Kansas State University, Mannattan, Kansas, February 21, 1983.

T. Wright, "A Note on Improving the Quality of Data Collected by Data Collection Systems," presented at the 5th National Meeting of the Evaluation Research Society, Baltinore, Maryland, October 28, 1982. 


\section{REFERENCES}

University of Southwestern Louisiana

${ }^{2}$ Technical Applications, ORNL.

${ }^{3}$ Ford Motor Company

${ }^{4}$ University of Georgia

${ }^{5}$ The Tobacco Institute, Inc.

Gak Ridge Associated Universities

Zuniversity of North Carolina

${ }^{8}$ Solid State Division, ORNL.

9 Metals and Ceramics Division, ORNL

10 Engineering Technology, $\mathrm{Y}-12$

1 University of Minnesota

12 Stanford University

13 University of California at Santa Barbara

14 Purdue University

15 Environmental Sciences Division, ORNL

16 University of South Carolina

17 North Carolina State University

18 University of Waterloo

19 Biology Division, ORNL

${ }^{20}$ Southern California College of Optometry

21 Chevron Research Company

${ }^{22}$ Georgia State University

23 Ohio State University

${ }^{24}$ University of Wisconsin

${ }^{25}$ Cornell University

${ }^{26}$ University of the South

27 University of Vermont

${ }^{28} \mathrm{Be} 11$ Telephone Laboratories

29 Baylor University

30 Separation and Materials Department, ORGDP

31 Electric Power Research Institute

32 The Aerospace Corporation

${ }^{33}$ Heaith and Safety Research Division, ORNL

${ }^{34}$ Operations Division, ORNL

35 University of Tennessee

${ }^{36}$ Fuel Recycling Division, ORNL

${ }^{37}$ Tennessee Technological University

${ }^{38}$ Combustion Engineering, Inc.

${ }^{39}$ Engineering Physics Division, ORNL

40 Energy Division, ORNL

41 AERE, Harwell, England 


\section{PART E. PROFESSIONAL ACTIVITIES}

Members of the Mathematics and Statistics Research Department participate in numerous activities in support of their professions. Some of their contributions are listed below.

C. K. Bayne

Member:

Technometrics Prize Committee

Progran Committee, 1982 DOE Statistical

Symposium

Instructor:

In-Hours Continuing Education Program

J. J. Beauchamp

Instructor:

In-Hours Continuing Education Program

Representative:

Professional Education Resource Committee, ORNL

1982 DOE Statistical Symposium

K. 0. Bowman

Member:

International Editorial Board, Communications in Statistics: Part B, Simulation and Computation 
American Statistical Association (ASA) and

Committee of Presidents of Statistical

Societies (COPSS) Committee of Representatives to the American Association for the

Advancernent of Science (AAAS) (Representative to Section $T$ )

Advisory Panel, AAAS, National Network of

Minority Women in Science

Steering Committee, 1984 SIAM Conference on

Computational statistics

Associate Editor: Journal of Statistical Computation and

Simulation

Contributing Editor: Current Index to Statistics

Lecturer:

Visiting Lecture Program in Statistics,

Committee of Presidents of Statistical

Societies (COPSS)

Organizer and

Chairman:

Symposium, AAAS Annual Meeting, Detroit, MI, 1983: "Sciences and Statistical Computing"

E. L. Frome

Member:

Organizing Committee, 3rd Coolfont Conterence

"The Analysis and Assessment of Ionizing

Radiation from Scientific and Statistical

Perspectives," Amarican Stattistical

Association (to be held July 10-15, 1983)

Research Planning Group for Uák kidge

Associated Universities - IIniversity of

North Carolina Cullaborative Studies of DOE Workers

Participant:

Program Review of the Center for Epidemio-

logic Studies, Oak. Ridge Associated

Universities, Chapel Hill, North Carolina,

October 25-26, 1982

Adjunct Professor: Department of Biostatistics, The University

of North Carolina 
R. E. Funderlic

Visiting Professor: Spring Semester, North Carolina State University

Organizer:

Numerical Analysis Seminar Series, North Carolina State University

Member:

W. Harrod's Ph.D. Committee, University of Tennessee

Numerical Analysis Curriculum Committee, North Carolina State University

Organizing Committee,

1982 Sparse Matrix Symposium

Coordinator:

University Relations Program,

Oak Ridge Associated Universities

D. G. Gosslee

Member:

Advisory Committee, Department of Statistics, Onio State University

Advisor:

International Commission for Protection

Against Environmental Mutagens and

Carcinogens

Representative:

Steering Committee, 1983 Statistics Symposium on National Energy Issues

L. J. Gray

Lecturer:

Department of Mathematics,

University of Tennessee

M. T. Heath

Instructor:

In-Hours Continuing Education Program

Member:

Organizing Committee,

1982 Sparse Matrix Symposium

Editor:

Sparse Matrix Software Catalog,

1982 Sparse Matrix Symposium 
T. L. Hebble

Member:

Instructor:

V. E. Kane

Secretary-Treasurer:

Represenlative:

W. E. Lever

Member:

T. J. Mitchell

Lecturer:

Associate Editor:

Chairman:

M. D. Morris

Instructor:

Lecturer:
Task Force on Experimental Joint Program of Task Group on Dissimilar Metal Weld for the ASTM-ASME-MPC Joint Committee on the Effect of Temperature on the Properties of Metals In-Hours Continuing Education Program

The Classification Society

Regional Advisory Board, Rinmetric Society Committee on Statistics and the Environment, American Statistical Association Steering Committee, 1982 DOE Statistical Symposium

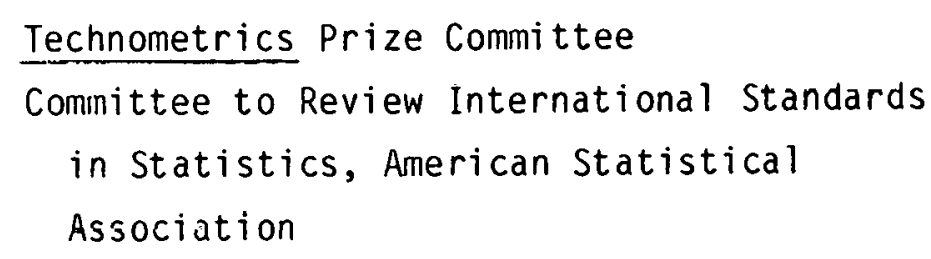

Graduate School of Biomedical Sciences, University of Tennessee - Uak Ridqe Technometrics

1982 Gordon Research Conference on Statistics in Chemict.ry and Chemical Engineering

In-Hours Continuing Education Program

Department of Statistics, University of Tennessee 
R. L. Schmoyer

Instructor:

Lecturer:

In-Hours Continuing Education Program

Traveling Lecture Program,

Oak Ridge Associated Universities

C. A. Serbin

Instructor:

Y-12 Computing Education Program

A. D. Solomon

Lecturer:

Departments of Mathematics and Computer

Science, University of Tennessee

Traveling Lecture Program,

Oak Ridge Associated Universities

V. R. R. Uppuluri

President:

East Tennessee Chapter of the Society for Risk Analysis

Treasurer:

Society for Risk Analysis

Oak Ridge Chapter of Sigma $X i$

Member:

Advisory Committee,

ORNL Office of Risk Analysis

Associate Editor:

Risk Analysis

Lecturer:

Visiting Lecture Program,

Mathematical Association of America

Director:

NATO Advanced Study Institute on:

Technology Assessment, Environmental Impact

Assessment and Risk Analysis

Instructor:

In-Hours Continuing Education Program

Chairman:

Workshop on Propagation of Uncertainties,

October 7-8, 1982 
R. C. Ward

Chairman:

Member:

Visiting Scholar:

D. G. Wilson

Member:

Lecturer:

Organizing Committee, 1982 Sparse Matrix Symposium Salary Survey Committee, Society for Industrial and Applied Mathematics (SIAM) Graduate Fellowship Selection Panel, ORNL Program Committee, 1984 SIAM Conference on

Computational Statistics Computer Science Department, Stanford University, Summer, 1982

Data Processing Advisory Committee, State Technical Institute, Knoxville Traveling Lecture Program, Society for Industrial and Applied Mathematics

T. Wright

Associate Professor: Department of Mathematics and Physics, Knoxville lonlege

Assistant Professor: Department of Statistics, University of Tennessee

Member:

Editorial Board, American Journal of Mathematfcal dild Mallayemeint sciences

Advisory Committee on Continuing Education, American Statistical Association

Lecturer: ORNL's Statistical Methods for Quality Improvement Course

Chairman:

Improvement of the Quality of Data

Collected by Data Collection Systems, November 11-12, 1982, Oak Ridge 
ARTICLES REVIEMED OR REFEREED FOR PERIOOICALS

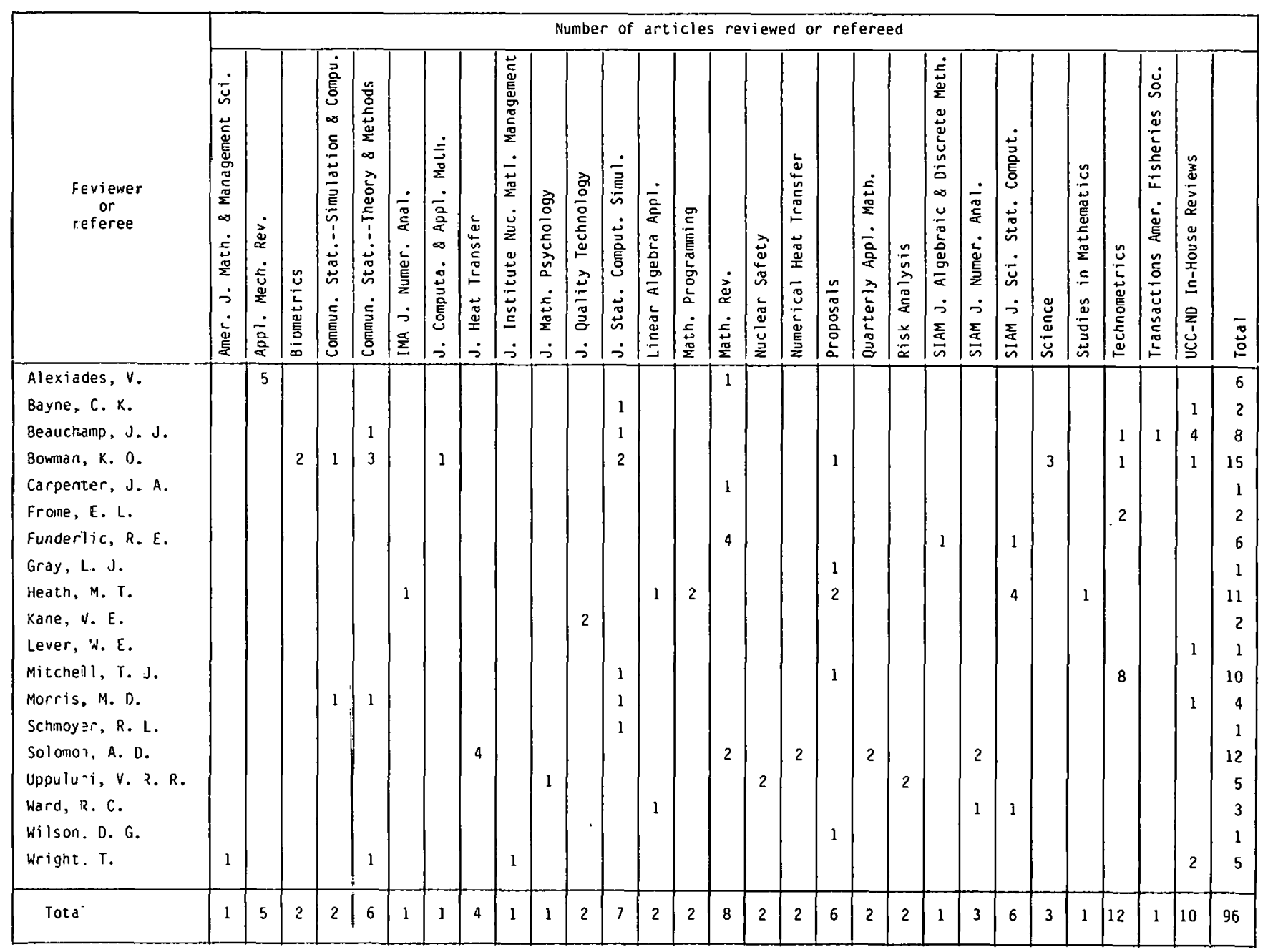


ORNL/CSD-118

Category Distribution UC-32

INTERNAL DISTRIBUTION

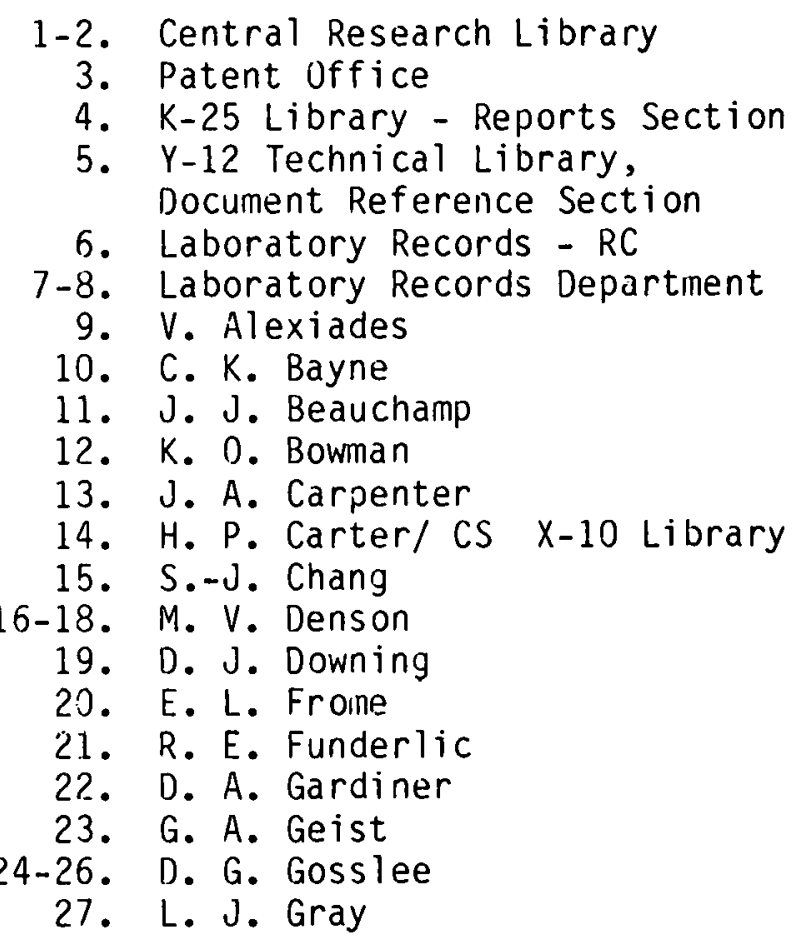

28. M. T. Heath

29. T. L. Hebble

30. E. Leach

31-33. W. E. Lever

34. L. P. Lewis

35. T. J. Mitchell

36. M. D. Morris

37. D. L. Poole

38. N. J. Price

39. T. S. Reed

40. D. C. Schlotzhauer

41. R. L. Schmoyer

42. C. A. Serbin

43-47. K. E. Shultz/

Biometrics Library

48-50. A. D. Solomon

51. J. S. Trent

52. V. R. R. Uppuluri

53-57. R. C. Ward

58-60. D. G. Wils on

61. T. Wright

\section{EXTERNAL DISTRIBUTION}

62. Dr. Jesse C. Arnold, Departmint of Statistics, Virginia Polytechnic Institute and State University, Blacksburg, VA 24061

63. Dr. Donald M. Austin, Division of Engineering, Mathematical and Geosciences, Office of Basic Energy Sciences, U.S. Department of Energy, Germantown Building ER-15, Room J-311, Washington, DC 20545

64. Dr. Richard E. Barlow, Industrial Engineering \& Operations Rescarch Departinent, University of Calffornia, 3115 Etcheverry Hall, Berkeley, CA 94720

65. Dr. A. P. Basu, Chairman, Department of Statistics, University of Missouri, Columbia, MO 65211

66. Dr. Peter Bloomfield, Department of Statistics, Princeton University, Princeton, NJ 08544 
67. Dr. Ralph A. Bradley, Department of Statistics and Computer Science, University of Georgia, Athens, GA 30602

68. Dr. Bill L. Buzbee, Computing Division, MS-B260, LoS Alamos National Laboratory, Los Alamos, NM 87545

69. Professor John Cannon, Department of Mathematics, Washington State University, Pullman, WA 99164

70. Dr. Jagdish Chandra, Mathematics Division, U.S. Army Research Office, P.0. Box 12211, Research Triangle Park, NC 27709

71. Dr. James S. Coleman, Division of Engineering, Mathematicai and Geosciences, Office of Basic Energy Sciences, U.S. Department of Erreryy, Germantown Building, ER.17, MC G-256, Washingt.on. DC 20545

72. Dr. James Corones, Ames Laboratory, Iowa Stat.e University, Ames, IA 50011

73. Dr. George J. Davis, Department of Mathematics, Georgia State University, Atlanta, GA 30303

74. Dr. Edward J. Dudewicz, Department of Statistics, Ohio State University, 1958 Neil Avenue, Columbus, $\mathrm{OH} 43210$

75. Dr. Lain S. Duff, Building 8.9, AERE Harwell, Oxon, Ox11 ORA, ENGLAND

76. Dr. Sherwood F. Ebey, Department of Mathematics, The University of the South, Sewanee, TN 37375

77. Dr. Marvin D. Erickson, Computer Technology, Systems Department, Pacific Northwest Laboratory, P.0. Box 999, Richland, WA 99352

78. Professor Antonio Fasano, Instituto Matematico U. Dini, V. Le Morgagni 67/A, 50134 Firenze, ITALY

79. Dr. James E. Gentle, IMSL, Inc., Sixth Floor GNB Building, 7500 Bellaire Blvd., Houston, TX 77036

80. Dr. J. Alan George, 16 Academy Crëscent, Waterluo, Ontario, CANADA N2L $5 \mathrm{H} \%$

81. Dr. Gene H. Golub, Computer Science Department, Stanford University, Stanford, CA 94305

82. Dr. Kläus Hinkelınan, Department of Statistics, Virginia Polytechnic Institute and State University, Blacksburg, VA 24061

83. Dr. D. G. Hoel, National Institute of Environmental Health Sciences, P.0. Box 12233, Research Triangle Park, NC 27709 
84. Dr. James W. Johnson, U. S. Nuclear Regulatory Commission, Washington, DC 20555

85. Dr. Victor E. Kane, P. 0. Box 1517A, NAAO Building, Ford Motor Company, Dearborn, MI 48121

86. Dr. M. A. Kastenbaum, Director of Statistics, The Tobacco Institute, Inc., 1875 I Street, NW, Suite 800, Washington, DC 20006

87. Dr. Robert J. Kee, Applied Mathematics Division, 8331, Sandia Laboratories, Livermore, CA 94550

88. Dr. Richard L. Lau, Mathematics Group, Office of Naval Research, 1030 East Green Street, Pasadena, CA 91106

89. Dr. Robert L. Launer, Mathematics Division, U.S. Army Research Office, P.0. Box 12211, Research Triangle Park, NC 27709

90. Professor Peter D. Lax, Courant Institute of Mathematical Sciences, New York University, 251 Mercer St., New York, NY 10012

91. Dr. Paul C. Messina, Applied Mathematics Division, Argonne National Laboratory, Argonne, IL 60439

92. Dr. George Michael, Computation Departinent, Lawrence Liverinore National Laboratory, P.0. Box 808, Livermore, CA 94550

93. Dr. R. H. Moore, Chief, Statistical Research Division, U.S. Bureau. of the Census, Washington, DC 20233

94. Dr. Basil Nichols, T-7, Mathematical Modeling and Analysis, Los Alamos National Laboratory, P.0. Box 1663, Los Alamos, NM 87545

95. Professor John Ockendon, Oxford University Computing Laboratory, 19 Parks Road, Oxford, ENGLAND

96. Maj. C. E. Oliver, Computational Mathematics Program, Directorate of Mathematical and Informational Sciences, Air Force Office of Scientific Research, Building 410, Bolling AFB, Washington, DC 20332

97. Dr. James M. Ortega, Head, Department of Applied Mathematics and Computer Science, University of Virginia, Charlottesville, VA 22901

98. Dr. Beresford N. Parlett, Department of Mathematics, University of California, Berkeley, CA 94720

99. Professor S. A. Patil, Department of Mathematics, Tennessee Technological University, Cookeville, TN 38501 
100. Dr. Ronald Peierls, Applied Mathematics Department, Brookhaven National Laboratory, Upton, NY 11973

101. Professor Robert J. Plemmons, Department of Mathematics and Computer Science, North Carolina State University, Raleigh, NC 27650

102. Dr. James C. T. Pool, Numerical Algorithms Group, Inc., 1131 Warren Avenue, Downers Grove, IL 60515

103. Dr. Carl Quong, Computer Science and Applied Mathematics Department, Lawrence Berkeley Laboratory, Berkeley, CA 94720

104. Dr. Douglas S. Robson, Biometrics Unit, Cornell University, Ithaca, NY 14853

105. Dr. Milton E. Rose, Director, ICASE, M/S 132C, NASA Langley Research Center, Hampton, VA 28665

106. Dr. Joan R. Rosenblatt, Deputy Director, Center for Applied Mathematics, National Bureau of Standards, Bldg. 101, Rm. A-438, Washington, DC 20234

107. Dr. David S. Scott, Department of Computer Sciences, Iniversity of Texas, Austin, TX 78712

108. Dr. Lawrence F. Shampine, Numerical Mathematics Division, 5642 , sandia Laboratories, P.0. Box 5800, N1buquerque, NM 87115

109. Dr. L. R. Shenton, Office of Computing and Information Service, Boyd Graduate Studies Bldg., University of Georgia, Athens, GA 30602

110. Dr. John N. Shoosmith, Mail Stop 125, NASA Langley Research Center, Hampton, VA 23665

111. Dr. Robert T. Smythe, Probability and Statistics Program, Directorate of Mathematical and Informational Sciences, Air Force Office of Scientific Research, Building 410, Bolling AFB, Washington, DC 20332

112. Professor Milton Sobel, Department of Mathematics, University of California, Santa Barbara, CA 93107

113. Dr. Daniel L. Solomon, Departinent of Statistics, North Carolina State University, Box 5457, Raleigh, NC 27650

114. Dr. E. M. Sparrow, Departinent of Mechanical Engineering, University of Minnesota, Minneapolis, MN 55455

115. Dr. George Stapleton, E-201, EV-32, Germantown, U.S. Department of Energy, Washington, DC 20545 
116. Dr. G. W. Stewart, Computer Science Department, University of Maryland, College Park, MU 20742

117. Professor Bruce Turnbull, 356 Upson Hall, Cornell University, Ithaca, NY 14853

118. Or. Charles F. VanLoan, Departinent of Computer Science, 405 Upson Hall, Ithaca, NY 14853

119. Dr. Richard S. Varga, Department of Mathematics, Kent State University, Kent, $\mathrm{OH} 44240$

120. Dr. Ray A. Waller, S-1, Statistics, Los Alamos National Laboratory, P.0. Box 1663, Los Alamos, NM 87545

121. Dr. Janes H. Wilkinson, Division of Numerical Analysis and Computer Science, National Physical Laboratory, Teddington, Middlesex, TW11 OLW, ENGLAND

122. Dr. John W. Wilkinson, School of Management, Rensselaer Polytechnic Institute, Troy, NY 12181

123. Dr. Dennis A. Wolf, Departinent of Preventive Medicine, University of iNisconsin, 502 Walnut Street, Madison, WI 53706

124. Office of Assistant Manager for Energy Research and Development, U.S. Departinent of Energy, Dak. Ridge Operations Office, Oak Ridge, TN 37830

125- Given distribution as shown in TIC-4500 under Mathematics and 306. Computers category. 